ARTICLE

\title{
Mitochondrial transcription factor $\mathrm{A}$ in ROR $\gamma \mathrm{t}^{+}$ lymphocytes regulate small intestine homeostasis and metabolism
}

Zheng Fu', Joseph W. Dean', Lifeng Xiong (10 1, Michael W. Dougherty (1) ${ }^{2}$, Kristen N. Oliff', Zong-ming E. Chen ${ }^{3}$, Christian Jobin (1) ${ }^{1,2}$, Timothy J. Garrett ${ }^{4} \&$ Liang Zhou (i] ${ }^{1 凶}$

ROR $\gamma \mathrm{t}^{+}$lymphocytes, including interleukin 17 (IL-17)-producing gamma delta T ( $\gamma \delta \mathrm{T} 17$ ) cells, T helper 17 (Th17) cells, and group 3 innate lymphoid cells (ILC3s), are important immune regulators. Compared to Th17 cells and ILC3s, $\gamma \delta T 17$ cell metabolism and its role in tissue homeostasis remains poorly understood. Here, we report that the tissue milieu shapes splenic and intestinal $\gamma \delta T 17$ cell gene signatures. Conditional deletion of mitochondrial transcription factor A (Tfam) in ROR $\gamma t^{+}$lymphocytes significantly affects systemic $\gamma \delta T 17$ cell maintenance and reduces ILC3s without affecting Th17 cells in the gut. In vivo deletion of Tfam in ROR $\gamma \mathrm{t}^{+}$lymphocytes, especially in $\gamma \delta T 17$ cells, results in small intestine tissue remodeling and increases small intestine length by enhancing the type 2 immune responses in mice. Moreover, these mice show dysregulation of the small intestine transcriptome and metabolism with less body weight but enhanced anti-helminth immunity. IL-22, a cytokine produced by ROR $\mathrm{t}^{+}$lymphocytes inhibits IL-13-induced tuft cell differentiation in vitro, and suppresses the tuft cell-type 2 immune circuit and small intestine lengthening in vivo, highlighting its key role in gut tissue remodeling.

\footnotetext{
${ }^{1}$ Department of Infectious Diseases and Immunology, College of Veterinary Medicine, University of Florida, Gainesville, FL, USA. ${ }^{2}$ Department of Medicine, University of Florida, Gainesville, FL, USA. ${ }^{3}$ Department of Laboratory Medicine and Pathology, Mayo Clinic, Rochester, MN, USA. ${ }^{4}$ Department of Pathology, Immunology and Laboratory Medicine, University of Florida, Gainesville, FL 32608, USA. ${ }^{\varpi}$ email: liangzhou497@ufl.edu
} 
$\mathrm{OR} \gamma \mathrm{t}^{+}$lymphocytes play an important role in immune homeostasis and disease pathogenesis, and include interleukin-17 (IL-17)-producing gamma delta $\mathrm{T}(\gamma \delta \mathrm{T} 17)$ cells, T helper 17 (Th17) cells, and group 3 innate lymphoid cells (ILC3s). Recent studies showed that cell metabolism is critical for host immunity regulation ${ }^{1-4}$. Progress has been made toward better understanding the metabolic regulation of Th17 cells and ILC3s. For example, Th17 cells, compared to quiescent naive $\mathrm{T}$ cells, exhibit decreased oxidative phosphorylation and increased glucose metabolism-orchestrated anabolism ${ }^{5}$. In contrast, ILC3s have been shown to rely on an mTORC1-dependent metabolic program that integrates glycolysis and mitochondrial production of reactive oxygen species (ROS) for ILC3 proliferation and function ${ }^{6} . \gamma \delta \mathrm{T} 17$ cells are a subset of innate-like $\mathrm{T}$ lymphocytes expressing the invariant gamma delta TCR $(\mathrm{TCR} \gamma \delta)$, and play a pivotal role in inflammation and autoimmunity as well as in cancer ${ }^{7-14}$. However, the current knowledge about the metabolic regulation in $\gamma \delta$ T cells, especially in $\gamma \delta \mathrm{T} 17$ cells, is limited.

Human and mouse mitochondrial genomes contain proteincoding genes that are essential for the mitochondrial respiratory chain ${ }^{15,16}$. Tfam is a nuclear gene encoding transcription factor crucial for mitochondrial DNA replication and transcription ${ }^{17-19}$. Germline knockout of Tfam or conditional deletion of Tfam in hematopoietic stem cells (HSC) in mice leads to embryonic lethality 20,21 . Tfam deficiency severely affects mitochondrial respiration in $\mathrm{T}$ regulatory $\left(\mathrm{T}_{\text {reg }}\right)$ cells and their maintenance and suppressive function ${ }^{22}$. Whether Tfam-mediated mitochondrial respiration plays a role in $\gamma \delta \mathrm{T}$ cell maintenance or function remains unknown.

Environmental stimuli play an important role in shaping local tissue immunity ${ }^{23-28}$. Transforming growth factor- $\beta$ (TGF- $\beta$ ), which promotes Foxp3 expression, is enriched in the gut to favor intestinal $\mathrm{T}_{\text {reg }}$ differentiation ${ }^{23}$. Furthermore, bile acid metabolites have been shown to control $\mathrm{T}$ helper (Th)17 and $\mathrm{T}_{\text {reg }}$ cell differentiation and also modulate ROR $\gamma \mathrm{t}^{+} \mathrm{T}_{\text {reg }}$ cell homeostasis in the gut ${ }^{24,25}$. An emerging concept of transcriptional imprinting on tissue-specific immune cells to allow them to adapt or respond to certain environmental stimuli has recently also been appreciated $^{29,30}$. For example, the aryl hydrocarbon receptor (Ahr), a ligand-dependent transcription factor and environmental sensor that can be activated by food and microbiome-derived metabolites in the gut 29,31 , is highly expressed by intestinal $\mathrm{T}_{\text {reg }}$ cells and innate lymphoid cells (ILCs) compared with their counterparts in other tissues ${ }^{32-34}$. Whether and how tissue milieu shapes $\gamma \delta \mathrm{T} 17$ cell gene signature have yet to be described.

The small intestine is the major organ for nutrient absorption, and also provides important immunity against mucosal pathogens. However, dysregulation of immune responses can cause inflammation and tissue damage of the small intestine (e.g., Crohn's disease). Modulation of the crosstalk between gut epithelial cells and immune cells are important for gut tissue homeostasis and disease pathogenesis. Tuft cells, a subset of specialized chemosensory epithelial cells, secrete IL-25 for ILC2 activation to control parasitic infection of helminths and protists ${ }^{35-38}$. Reciprocally, ILC2s can secrete IL-13 to promote intestinal tuft cell differentiation and proliferation. Enhanced ILC2 function has been shown to increase the number of small intestinal secretory epithelial cells including tuft cells, resulting in tissue remodeling and lengthening ${ }^{38}$. However, host cellular mechanism responsible for regulation of the tuft cell-ILC2 circuit in mice is unclear.

Here we show that $\gamma \delta \mathrm{T} 17$ cells were highly dependent on mitochondrial metabolism for their maintenance. Intestinal $\gamma \delta \mathrm{T} 17$ cells had a unique transcriptional program with an adaptation to environmental stimuli by engaging the Ahr pathway and TGF- $\beta$ pathway. Genetic ablation of Tfam in ROR $\gamma \mathrm{t}^{+}$lymphocytes led to a systemic decrease of $\gamma \delta$ T17 cells and a reduction of ILC3s but not Th17 cells in the gut, concomitant with the substantial increase of intestinal type 2 immune responses (ILC2s and Th2 cells), and small intestine tissue remodeling and inflammation in mice. Our data further indicated a key role for ROR $\gamma \mathrm{t}^{+}$lymphocyte effector cytokine IL-22 in regulation of the tuft cell-type 2 immune circuit and small intestine lengthening.

\section{Results}

Tfam deficiency affects $\gamma \delta \mathrm{T} 17$ cell maintenance. Compared to Th17 cells and ILC3s, little is known about metabolic regulation of $\gamma \delta \mathrm{T} 17$ cells. Two populations of $\gamma \delta \mathrm{T}$ cells could be defined based on CD44 and CD45RB surface expression in the spleen ${ }^{39-41}$. CD $44^{\text {medium }}$ CD $45 R B^{\text {high }} \gamma \delta \mathrm{T}$ cells, AKA $\gamma \delta \mathrm{T} 1$ cells, expressed Tbet and produced IFN- $\gamma$. In contrast, CD $44^{\text {high }} \mathrm{CD} 45 \mathrm{RB}^{-}$ $\gamma \delta \mathrm{T}$ cells, AKA $\gamma \delta \mathrm{T} 17$ cells, expressed ROR $\gamma \mathrm{t}$ and produced IL-17 (Supplementary Fig. 1a, b). In order to characterize the mitochondrial metabolisms of these two subsets of $\gamma \delta \mathrm{T}$ cells, we first determined the mitochondrial content and activity. Compared with $\gamma \delta \mathrm{T} 1$ cells, splenic $\gamma \delta \mathrm{T} 17$ cells contained more mitochondrial mass and/or potential as revealed by mitochondrial staining of MitoTracker-Deep Red (Fig. 1a-c). Higher mitochondrial membrane potential in $\gamma \delta \mathrm{T} 17$ cells was further indicated by tetramethylrhodamine ethyl ester (TMRE) staining (Fig. 1d, e). Furthermore, $\gamma \delta \mathrm{T} 17$ cells generated more mitochondrial-specific reactive oxygen species (ROS), an indicator of mitochondrial activity as revealed by MitoSOX ${ }^{\mathrm{m}}$ Red staining (Fig. 1d, e). Tfam expression, which is critical for regulating mitochondrial gene replication and transcription ${ }^{20}$, was higher in $\gamma \delta \mathrm{T} 17$ cells than in $\gamma \delta \mathrm{T} 1$ cells (Fig. 1f). Accordingly, elevated mitochondrial DNA content, mitochondrial gene expression (e.g., mt-Nd1, mt-Cytb, mt-Atp6), and cellular ATP production were observed in $\gamma \delta \mathrm{T} 17$ cells than in $\gamma \delta \mathrm{T} 1$ cells (Fig. 1g, $\mathrm{h}$ and Supplementary Fig. 1c). However, uptake of 2-(N-(7-nitrobenz-2-oxa-1,3-diazol-4-yl) amino)-2-deoxyglucose (2-NBDG), a fluorescent glucose analog for monitoring glucose uptake, did not show significant difference between $\gamma \delta \mathrm{T} 17$ and $\gamma \delta \mathrm{T} 1$ cells (Supplementary Fig. 1d, e). In addition, expression of several key genes involved in glycolysis (e.g., Slc2a1, Slc2a3, Hk1, Pkm, Pdk1, and Ldha) did not show a significant difference between $\gamma \delta \mathrm{T} 17$ cells and $\gamma \delta \mathrm{T} 1$ cells (Supplementary Fig. 1f). Together, these data suggest that $\gamma \delta \mathrm{T} 17$ cells exhibit higher mitochondrial mass and activity compared with $\gamma \delta \mathrm{T} 1$ cells.

To further understand the role of mitochondrial metabolism in $\gamma \delta \mathrm{T}$ cells, we crossed the mice carrying loxP-flanked Tfam alleles $\left(T f a m^{f l / f l}\right)$ with $T c r d^{C r e E R}$ mice in which Cre recombinase nuclear localization and subsequently gene deletion in $\gamma \delta \mathrm{T}$ cells are induced by tamoxifen treatment ${ }^{42}$ to specifically delete Tfam in $\gamma \delta \mathrm{T}$ cells (hereafter as Tfam ${ }^{l / f l} \mathrm{Tcrd}^{\mathrm{CreER}}$ mice). Results showed that deletion of the floxed Tfam locus in both $\gamma \delta \mathrm{T} 1$ and $\gamma \delta \mathrm{T} 17$ cells, but not in non- $\gamma \delta$ T lymphocytes in Tfam ${ }^{f l / f l}$ Tcrd CreER mice upon tamoxifen treatment (Supplementary Fig. 1g), resulting in decreased mitochondrial mass and activity in both $\gamma \delta \mathrm{T} 1$ and $\gamma \delta \mathrm{T} 17$ cells of $\mathrm{Tfam}^{\mathrm{fl} / \mathrm{fl}} \mathrm{Tcrd} \mathrm{CreER}$ mice compared with their littermate controls (Supplementary Fig. 1h, i). Notably, while splenic ROR $\gamma \mathrm{t}^{-} \gamma \delta \mathrm{T}$ cells, which include $\gamma \delta \mathrm{T} 1$ cells, did not show a significant reduction, $\mathrm{ROR} \gamma \mathrm{t}^{+} \gamma \delta \mathrm{T}$ (i.e., $\gamma \delta \mathrm{T} 17$ ) cell percentages and numbers were significantly decreased in Tfam ${ }^{f l / f l}$ Tcrd CreER mice compared to their littermate controls upon tamoxifen treatment (Fig. 1i, j). Together, these results suggested that Tfam is important in regulating $\gamma \delta \mathrm{T} 17$ but not $\gamma \delta \mathrm{T} 1$ cell maintenance, consistent with the higher mitochondrial content and activity of $\gamma \delta \mathrm{T} 17$ cells compared with $\gamma \delta \mathrm{T} 1$ cells.

Tfam is critical for ILC3 and $\gamma \delta$ T17 cell maintenance in the gut. Under steady-state condition, $\gamma \delta T 17$ cells, together with ILC3s and Th17 cells that express ROR $\gamma$ t, are predominantly 


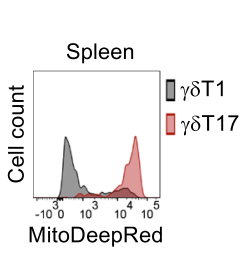

b

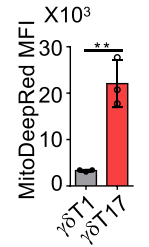

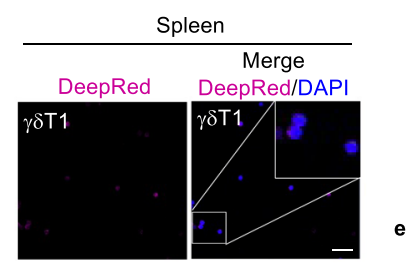

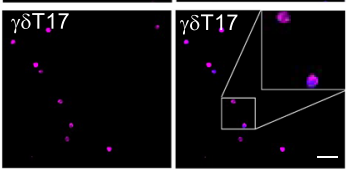

g
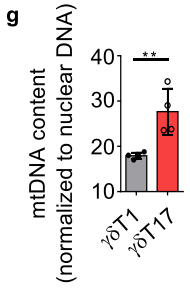

j

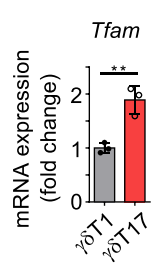

h
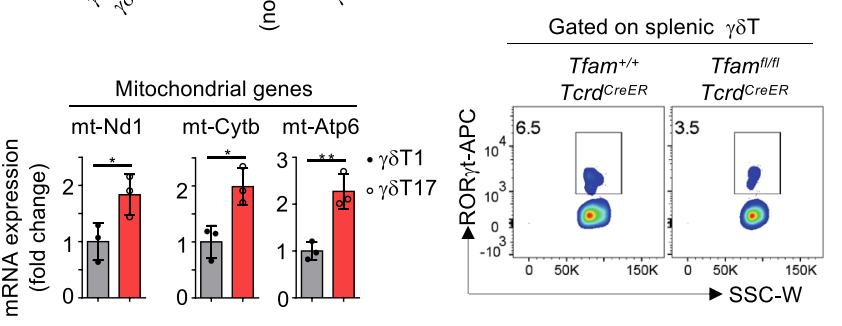

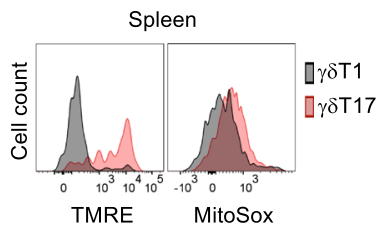

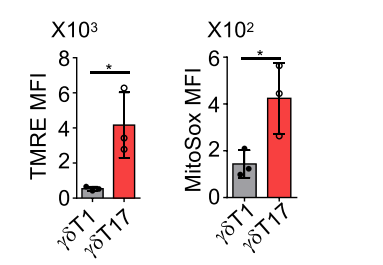

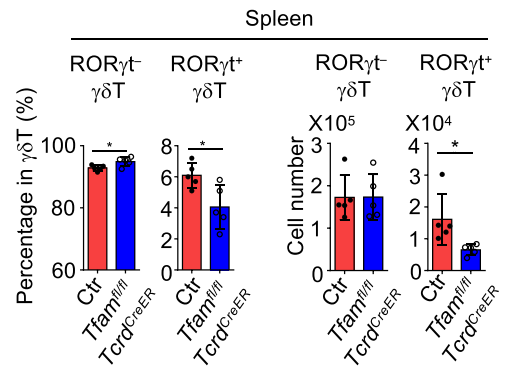

Fig. 1 Tfam deficiency affects $\boldsymbol{\gamma} \boldsymbol{\delta} \mathbf{T 1}$ and $\boldsymbol{\gamma} \boldsymbol{\delta} \mathbf{T 1 7}$ cells differentially. a MitoTracker-Deep Red staining in splenic $\gamma \delta T 1$ and $\gamma \delta T 17$ cells by flow cytometry. Representative data of three independent experiments. b MitoTracker-Deep Red mean fluorescence intensity $(\mathrm{MFI})$ in $\mathbf{a}(n=3$ for each group) ( $\star \star x=$ 0.0032). Compiled data from one experiment. c Confocal analysis of MitoTracker-Deep Red staining in splenic $\gamma \delta T 1$ and $\gamma \delta T 17$ cells. Scale bar, $50 \mu m$. Representative data of two independent experiments. d Tetramethylrhodamine, ethyl ester (TMRE) and MitoSox ${ }^{\mathrm{TM}}$ Red staining in splenic $\gamma \delta T 1$ and $\gamma \delta T 17$ cells by flow cytometry. Representative data of three independent experiments. e TMRE ( $P=0.0281)$ and MitoSox ${ }^{\mathrm{TM}} \mathrm{MFI}\left({ }^{\star} P=0.0404\right)$ in $\mathbf{d}(n=3$ for each group). Compiled data from one experiment. $\mathbf{f}$ Expression of Tfam measured by quantitative real-time PCR ( $q R T-P C R$ ) in the splenic $\gamma \delta T 1$ and $\gamma \delta T 17$ cells ( $n=3$ for each group) ( ${ }^{\star \star} P=0.0053$ ). Each dot indicated a biological repeat of individual RNA sample pooled from two mice. Compiled data from two independent experiments. $\mathbf{g}$ Mitochondrial DNA content measured by qPCR (mt-Nd1 compared to nuclear gene $H b b)$ in splenic $\gamma \delta T 1$ and $\gamma \delta T 17$ cells $(n=4$ for each group) ( $\left.{ }^{\star \star} P=0.0091\right)$. Compiled data from two independent experiments. h Expression of mitochondrial gene mt-Nd1 ( $\left.P=0.0427\right)$, $\mathrm{mt}-\mathrm{Cytb}$ $\left({ }^{\star} P=0.0177\right)$, and mt-Atp6 ( $\left.{ }^{\star \star} P=0.0062\right)$ by qRT-PCR in splenic $\gamma \delta T 1$ and $\gamma \delta T 17$ cells $(n=3$ for each group). Each dot indicated a biological repeat of individual RNA sample pooled from two mice. Compiled data from two independent experiments. i ROR $\gamma t$ expression by splenic $\gamma \delta T$ cells by flow cytometry in mice with indicated genotypes. Representative data of three independent experiments. Mice were treated with tamoxifen daily for 5 days. Data were collected 3 weeks after the last tamoxifen injection. $\mathbf{j}$ ROR $\gamma \mathrm{t}^{-} \gamma \delta \mathrm{T}$ and ROR $\gamma \mathrm{t}^{+} \gamma \delta \mathrm{T}$ (i.e., $\left.\gamma \delta \mathrm{T} 17\right)$ cell percentages (ROR $\gamma \mathrm{t}^{-} \gamma \delta \mathrm{T}$, ${ }^{\star} P=0.0299$; $\left.\mathrm{ROR}_{\mathrm{t}}{ }^{+} \gamma \delta \mathrm{T},{ }^{\star} P=0.0218\right)$ within total splenic $\gamma \delta \mathrm{T}$ cells as shown in $\mathbf{i}$ and absolute cell numbers (ROR $\left.\gamma \mathrm{t}^{-} \gamma \delta \mathrm{T}, P=0.9856 ; \mathrm{ROR} \gamma \mathrm{t}^{+} \gamma \delta \mathrm{T}:{ }^{\star} P=0.0311\right)(n=5$ for each group). Compiled data from two independent experiments. Ctr included Tfam $+/+T c r d C r e E R$ and Tfamfl/ $+T c r d C r e E R$. Data are shown as mean \pm SD in b, e-h, $\mathbf{j}$.

present in the mucosal tissues such as the intestine ${ }^{34,43}$. Unlike ROR $\gamma \mathrm{t}^{-} \gamma \delta \mathrm{T}$ cells predominantly in the intraepithelial lymphocyte (IEL) compartment, $\gamma \delta \mathrm{T} 17$ cells were found in the lamina propria lymphocytes (LPL) of the gut (Supplementary Fig. 2 for gating strategy and Supplementary Fig. 3a). Because of relatively inefficient deletion of Tfam in $\gamma \delta \mathrm{T} 17$ cells of $T f a m^{f l / f l} T c r d{ }^{C r e E R}$ mice (Supplementary Fig. 1g) and to further determine the role of $T f a m$ in $\gamma \delta T 17$ cells, we crossed Tfam ${ }^{f l / f l}$ mice with Rorc-cre mice (hereafter as $T f a m^{f l / f l}$ Rorc-cre mice) in which Tfam was deleted in ROR $\gamma \mathrm{t}^{+}$lymphocytes. Results showed an efficient deletion of the floxed Tfam locus in ROR $\gamma \mathrm{t}^{+}$lymphocytes, including $\gamma \delta \mathrm{T} 17$ cells, ILC3s, and Th17 cells (Supplementary Fig. 3b). There were no significant changes in CD4, CD8 single (SP) or double positive (DP) cells in the thymi of $T f_{a m}{ }^{f l / f l}$ Rorc-cre mice compared to littermate controls (Supplementary Fig. 3c, d). In addition, CD4 ${ }^{+}$ or $\mathrm{CD}^{+} \mathrm{T}$ cells were not significantly changed in the spleens of Tfam $^{f l f l}$ Rorc-cre mice (Supplementary Fig. 3e, f), suggesting that Tfam deficiency did not affect $\mathrm{CD}^{+}$or $\mathrm{CD}^{+} \mathrm{T}$ cell development.

Intriguingly, at week 3 of age, we observed a reduction of ROR $\gamma \mathrm{t}^{+}$lymphocytes, especially $\gamma \delta \mathrm{T} 17$ cells in the small intestine of Tfam ${ }^{\text {flflfl}}$ Rorc-cre mice (Fig. $2 \mathrm{a}, \mathrm{b}$ ). The cellular ATP production was also decreased in Tfam-deficient $\gamma \delta \mathrm{T} 17$ cells compared with control $\gamma \delta \mathrm{T} 17$ cells (Supplementary Fig. 3g). We noticed inconsistent success rate of small intestinal lymphocyte preparation in older mice, presumably due to tissue and cellular changes in the gut (see below). Thus, we examined dynamic changes of lymphocytes in the large intestine of mice at different ages. In 1week-old Tfam ${ }^{f l / f l}$ Rorc-cre mice, both $\gamma \delta \mathrm{T} 17$ cells and ILC3s did not show a significant change compared to their littermate control mice, suggesting that Tfam deletion does not affect the early development of $\gamma \delta$ T17 cells and ILC3s (Fig. $2 c$ and Supplementary Fig. $3 \mathrm{~h}$ ). In 3-week-old Tfam fl/fl Rorc-cre mice, $\gamma \delta \mathrm{T} 17$ cells were significantly decreased, while ILC3s did not show an obvious change compared to their littermate control mice (Fig. 2c and Supplementary Fig. 3i). By 6 weeks of age, $\gamma \delta \mathrm{T} 17$ cells were markedly reduced, and a substantial reduction of ILC3s was also apparent (Fig. $2 c$ and Supplementary Fig. 3j). In contrast, Th17 cells had no significant change in $\mathrm{Tfam}^{\mathrm{fl} / \mathrm{fl} \text { Rorc-cre }}$ mice at 6 weeks of age compared to littermate control mice (Fig. 2d and Supplementary Fig. 3j). It has been reported that the $\mathrm{T}$ cell receptor (TCR) chain $\mathrm{V} \gamma 2$ or $\mathrm{V} \gamma 4$ represented the majority of $\gamma \delta \mathrm{T} 17$ cells in different tissues ${ }^{11,44-46}$. Consistently, the majority of $\gamma \delta \mathrm{T} 17$ cells in the gut LPL expressed the TCR chain 
a

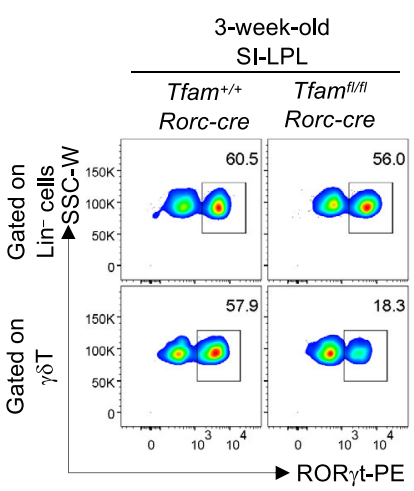

b

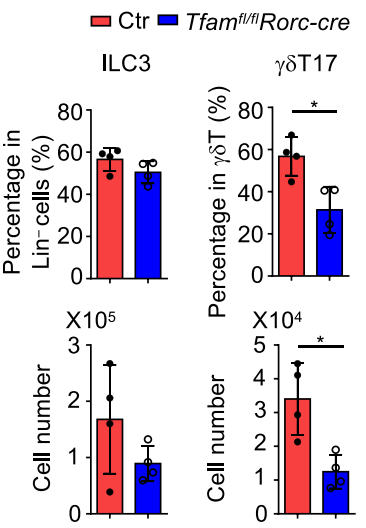

c
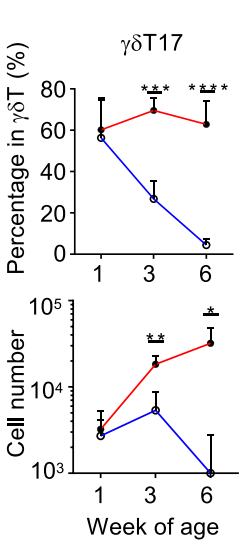

d

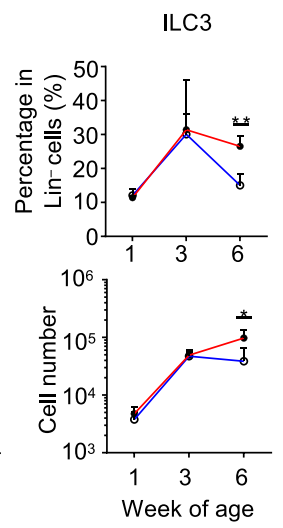

Th17
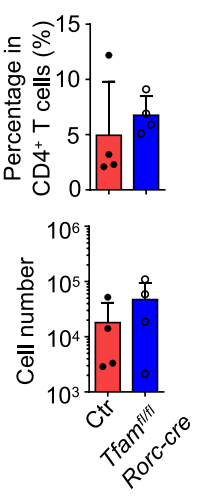

e Gated on $\gamma \delta \mathrm{T}$
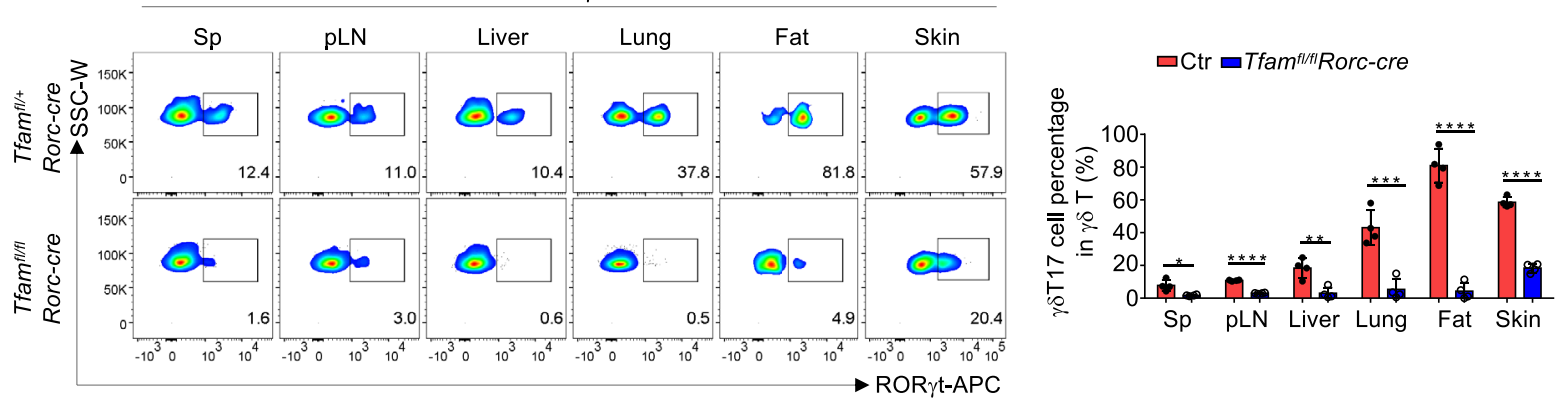

Fig. 2 Tfam is critical for $\boldsymbol{\gamma} \boldsymbol{\delta}$ T17 cell and ILC3 maintenance. a Flow cytometry analyses of ILC3s (upper panel, gated on lineage-negative lymphocytes) and $\gamma \delta T 17$ cells (lower panel, gated on $\gamma \delta T$ cells) from small intestine lamina propria (LPL) of 3-week-old mice of indicated genotypes. Representative data of three independent experiments. Lineage markers in $\mathbf{b}$ and $\mathbf{c}$ include CD3, CD5, CD19, Ly6G, CD11b, and CD11c. b $\gamma \delta T 17$ cell percentages in total $\gamma \delta T$ cells (percentage, ${ }^{\star} P=0.0120$; cell number, $\left.{ }^{\star} P=0.0106\right)$, and ILC3 percentages in lineage-negative $\left(\right.$ Lin $\left.^{-}\right)$cells (upper panel) $(P=0.1575)$ and cell numbers (lower panel) $(P=0.1725)$ from the small intestine of mice shown in $\mathbf{a}(n=4$ for each group). Compiled data from two independent experiments. $\mathbf{c} \gamma \delta \mathrm{T} 17$ cell percentages in total $\gamma \delta$ T cells and ILC3 percentage in lineage-negative cells (upper panel) ( $\gamma \delta$ T17: week $3,{ }^{\star \star \star} P=0.0002$, week 6, ${ }^{\star \star \star \star} P<0.0001$; ILC3: week $\left.6,{ }^{\star \star} P=0.0019\right)$ and cell numbers (lower panel) $\left(\gamma \delta T 17\right.$ : week $3,{ }^{\star \star} P=0.0035$, week $6,{ }^{\star} P=0.0101$; ILC3: week 6, $\left.{ }^{\star} P=0.0396\right)$ of the large intestine of mice at indicated ages ( $n=4$ for each group). The rest time points showed no significance between $\mathrm{Ctr}$ and Tfam $\mathrm{fl} / \mathrm{fl}$ Rorc-cre $(P>0.05)$. Compiled data from two independent experiments. $\mathbf{d}$ Th17 cell percentages in total CD4+ ${ }^{+}$cells (upper panel) $(P=0.1705)$ and cell numbers (lower panel) $(P=0.0950)$ of the large intestine of 6 -week-old age mice ( $n=4$ for each group). Compiled data from two independent experiments. e RORyt expression in $\gamma \delta T$ cells of various organs (Sp spleen, pLN peripheral lymph nodes) of mice with indicated genotypes measured by flow cytometry. Representative data of three independent experiments. $\mathbf{f} \delta \mathrm{T} 17$ cell percentages in total $\gamma \delta \mathrm{T}$ cells from the various organs as shown in $\mathbf{e}\left(n=4\right.$ for each group). Sp, ${ }^{\star} P=0.0121 ; \mathrm{pLN}$, ${ }^{\star \star \star \star} P<0.0001$; liver, ${ }^{\star \star} P=0.0043$; lung, ${ }^{\star \star \star} P=0.0009$; fat, ${ }^{\star \star \star \star} P<0.0001$; skin, ${ }^{\star \star \star \star} P<0.0001$. Compiled data from two independent experiments. Ctr included $\mathrm{Tfam}^{+/+}, \mathrm{Tfam}^{\mathrm{fl} / \mathrm{H}}, \mathrm{Tfam}^{\mathrm{fl} / \mathrm{fl}, \mathrm{Tfam}}{ }^{+/+}$Rorc-cre, and $\mathrm{Tfam}^{\mathrm{fl} /}+$ Rorc-cre mice. Data are shown as mean \pm SD in b-d, f.

$\mathrm{V} \gamma 2$ or $\mathrm{V} \gamma 4$, and both $\mathrm{ROR} \gamma \mathrm{t}^{+} \mathrm{V} \gamma 2^{+}$and $\mathrm{ROR} \gamma \mathrm{t}^{+} \mathrm{V} \gamma 4^{+}$were markedly reduced in 6-week-old Tfam ${ }^{\text {fl/fl }}$ Rorc-cre mice (Supplementary Fig. $3 k, 1)$. Of note, $\gamma \delta \mathrm{T} 17$ cells also showed a substantial systemic decrease in various lymphoid and non-lymphoid tissues of the mice (i.e., spleen (Sp), peripheral lymph nodes ( $\mathrm{pLN}$ ), liver, lung, fat, and skin) of Tfam fl/fl Rorc-cre mice at 6 weeks of age (Fig. 2e, f), suggesting a crucial requirement for Tfam in systemic $\gamma \delta \mathrm{T} 17$ cell maintenance. On a per cell basis, similar amounts of IL-17 and IL-22 were made by Tfam-deficient $\gamma \delta$ T17 cells and ILC3s compared to Tfam-sufficient cells, suggesting that Tfam does not regulate the effector cytokine production of $\gamma \delta \mathrm{T} 17$ cells and ILC3s (Supplementary Fig. 3m-p). Together, these data indicate that Tfam deficiency in ROR $\gamma \mathrm{t}^{+}$lymphocytes selectively affect the maintenance of $\gamma \delta$ T17 cells and ILC 3 s but not Th17 cells.

Tfam deficiency in $\gamma \delta \mathrm{T} 17$ cells perturb the small intestine homeostasis. Upon close examination of the intestinal phenotype

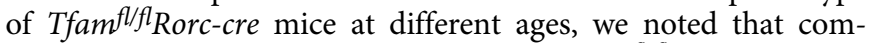
pared to their littermate controls, Tfam ${ }^{f l f l}$ Rorc-cre mice developed a progressive small intestine lengthening starting from 8 -week-old age (Fig. 3a, b). In contrast, the large intestine length had no difference even until 12-week-old age (Supplementary Fig. 4a). Histological analysis showed pathological changes, including increased inflammatory infiltration in intraepithelial and lamina propria compartments, goblet cell and crypt hyperplasia, as well as muscularis propria hypertrophy in the small intestine of $T f a m^{f l / f l}$ Rorc-cre mice (Fig. 3c, d).

To further determine the effect of Tfam deletion in T cells, we generated $\mathrm{Tfam}^{f l / f l} \mathrm{Cd} 4$-cre mice, in which Tfam was deleted in $\mathrm{CD}^{+}$and $\mathrm{CD}^{+} \mathrm{T}$ cells. Our data showed that $\mathrm{Tfam}^{f l / f l} \mathrm{Cd} 4$-cre mice had normal peripheral $\mathrm{CD}^{+}$and $\mathrm{CD}^{+}{ }^{+} \mathrm{T}$ cells (Supplementary Fig. 4b, c). Furthermore, Tfam $^{f l / f l} C d 4$-cre mice had normal ILC3s and $\gamma \delta \mathrm{T} 17$ cells (Supplementary Fig. $4 \mathrm{~d}, \mathrm{e}) . \mathrm{Of}$ note, $\mathrm{Tfam}^{f l / f l} \mathrm{Cd} 4$-cre mice did not have increased small intestine length compared with their littermate controls even at older age (3-month-old) (Supplementary Fig. 4f, g). In addition, Tfam ${ }^{\text {fl }}$ ${ }^{f l}$ Cd4-cre mice and Tfam ${ }^{f l / f l}$ Rorc-cre mice had reduced $\mathrm{T}_{\text {reg }}$ cells but normal Th17 cells in the gut (Supplementary Fig. 4h-k), consistent with our previous findings showing an important role 


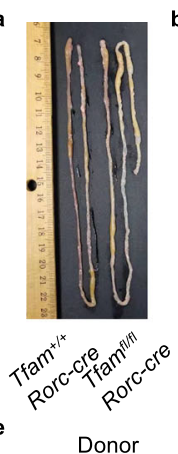

e Donor

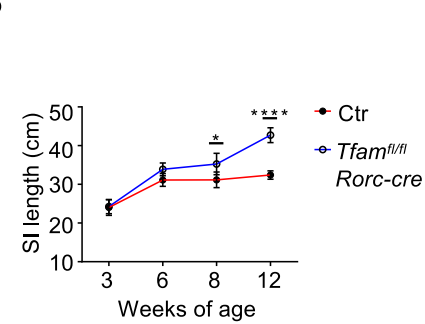

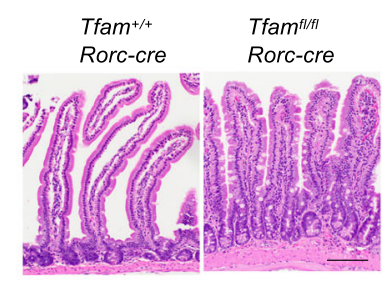

d

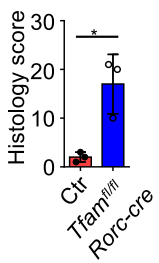

g

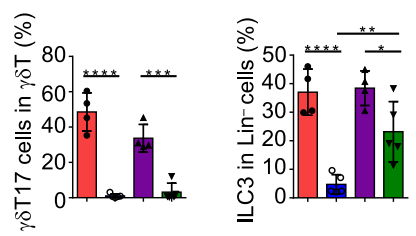

h

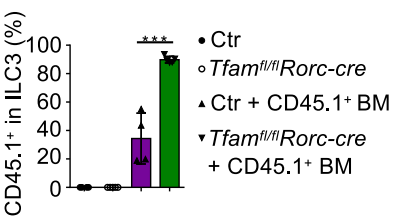

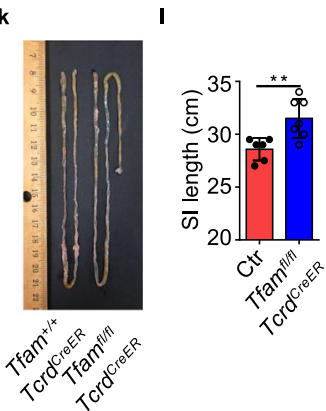

Fig. 3 Tfam deficiency in $\boldsymbol{\gamma} \boldsymbol{\delta} \mathbf{T 1 7}$ cells cause small intestine lengthening. a Picture of the small intestine of 8 -week-old littermate Tfam $+/+R o r c-c r e$ and

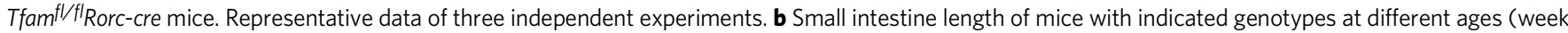
3, $P=0.8542$; week 6, $P=0.056$; week $8,{ }^{\star} P=0.03853$; week 12, ${ }^{\star \star \star \star} P<0.0001$ ). Ctr, $n=5$ for 3-week-old and 12-week-old age, $n=4$ for 6-week-old age, $n=3$ for 8 -week-old age, Tfam ${ }^{f / f l}$ Rorc-cre, $n=4$. Compiled data from three independent experiments. c Hematoxylin and eosin (H\&E) staining of the small intestine from 12-week-old mice with indicated genotypes. Representative data of two independent experiments. Scale bar, $100 \mu \mathrm{m}$. $\mathbf{d}$ Histology score of the small intestine ( $n=3$ for each group) ( $\left.{ }^{\star} P=0.0135\right)$. Each dot represented the data from an individual mouse. Compiled data from one experiment. e ROR $\mathrm{Rt}$ and CD45.1 expression in Lin ${ }^{-}$cells (upper panel) or total $\gamma \delta T$ cells (lower panel) measured by flow cytometry in Ctr or Tfam ${ }^{f / f f l}$ Rorc-cre mice with or without CD45.1+ wild-type (WT) bone marrow (BM) transfer. Representative data of two independent experiments. f Percentages of $\gamma \delta \mathrm{T} 17$ cells in total $\gamma \delta \mathrm{T}$ cells (Ctr

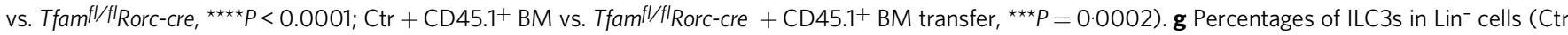
vs. Tfam ${ }^{f / / f l}$ Rorc-cre, ${ }^{\star \star \star \star} P<0.0001 ; C t r+C D 45.1^{+}$BM vs. Tfam ${ }^{f l / f l}$ Rorc-cre $+C D 45.1^{+}$BM, ${ }^{\star} P=0.0382 ;$ Tfam ${ }^{f l / f l}$ Rorc-cre vs. Tfam ${ }^{f / / f l}$ Rorc-cre $+C D 45.1^{+}$BM, $\left.{ }^{\star \star} P=0.0059\right)$. h Percentages of CD45.1 $1^{+}$ILC3s in total ILC3s (Ctr + CD45.1+ BM vs. Tfam ${ }^{f l / f l}$ Rorc-cre + CD45.1 ${ }^{+}$BM, $\left.{ }^{\star \star \star} P=0.0002\right) . \mathbf{i}$ Picture of the small intestine. j Small intestine length. Compiled data from two independent experiments in $\mathbf{f}-\mathbf{h}$, j (Ctr vs. Tfam fl/fl/Rorc-Cre, ${ }^{\star \star} P=0.0037 ; \mathrm{Ctr}+\mathrm{CD} 45.1^{+} \mathrm{BM}$ vs. Tfam $^{f l / f l}$ Rorc-cre $\left.+\mathrm{CD} 45.1^{+} \mathrm{BM},{ }^{\star \star} P=0.0014\right)\left(n=4\right.$ for $\mathrm{Ctr}$ with or without BM transfer groups and $n=5$ for Tfam ${ }^{f l / f l}$ Rorc-cre mice with or without BM transfer groups). $\mathbf{k}$ Picture of the small intestine of mice with indicated genotypes. Five-week-old age mice were treated with tamoxifen ( $2 \mathrm{mg} / \mathrm{mouse}$ by intraperitoneal injection) daily for 5 days. Data were collected 3 weeks after the last tamoxifen injection. I Small intestine length. Compiled data from three

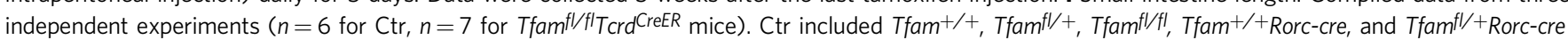
mice in $\mathbf{b}, \mathbf{d}, \mathbf{f}-\mathbf{h}, \mathbf{j}\left({ }^{* \star} P=0.0060\right)$. Ctr included $T f a m^{+/+} T c r d C r e E R$ and $T f a m^{f l /}+T c r d C r e E R$ mice in $\mathbf{I}$. Data are shown as mean $\pm S D$ in $\mathbf{b}, \mathbf{d}, \mathbf{f}-\mathbf{h}, \mathbf{j}, \mathbf{I}$.

of Tfam in regulating gut $\mathrm{T}_{\text {reg }}$ cells ${ }^{22}$. Since Tfam is deleted in $\mathrm{CD}^{+} \mathrm{T}$ cells in both Tfam ${ }^{f l / f l} \mathrm{Cd} 4$-cre and Tfam $^{\text {fl/fl }}$ Rorc-cre mice, these data suggest that the intestine lengthening observed in Tfam $^{\text {fl/fl }}$ Rorc-cre mice may be independent of $\mathrm{CD}^{+} \mathrm{T}$ cells, including $\mathrm{Th} 17$ and $\mathrm{T}_{\text {reg }}$ cells.

We further transferred the congenically marked wild-type (WT) bone marrow (BM) from the adult CD45.1/CD45.1 mice to the halflethally irradiated 4-week-old littermate control or $\mathrm{Tfam}^{\text {fl/fl }}$ Rorc-cre mice and examined their phenotypes 5 months after the bone marrow transfer. $\gamma \delta \mathrm{T} 17$ cells were not restored after WT BM transfer (Fig. 3e, f), consistent with the fact that $\gamma \delta \mathrm{T} 17$ cells can be generated from the fetal thymus but not the adult bone marrow ${ }^{47,48}$. Although about twofold reduced compared to WT mice, significant restoration of ILC3s (specifically, CD45.1 ${ }^{+}$donor-derived) by BM transfer (Fig. 3e, g, h) could not revert the phenotype of small intestine lengthening in $T f a m^{f l / f l}$ Rorc-cre mice (Fig. $3 \mathrm{i}$, j). Of note, these data did not rule out the contribution of ILC3s, but suggested that Tfam deficiency in $\gamma \delta \mathrm{T} 17$ cells was likely a major contributor to 
small intestine lengthening in Tfam ${ }^{f l f l}$ Rorc-cre mice. This interpretation was further supported by small intestine lengthening in $\mathrm{Tfam}^{f l / f l} \mathrm{Tcrd} \mathrm{CreER}^{\mathrm{C}}$ mice, which had deletion of Tfam in $\gamma \delta \mathrm{T}$ cells but not in ILC3s (Fig. 3k, 1 and Supplementary Fig. 4l-n). Collectively, our results suggest that Tfam plays a pivotal role in regulating $\gamma \delta \mathrm{T} 17$ cell maintenance and small intestine tissue remodeling.

Tissue-specific transcriptome signature of $\gamma \delta \mathrm{TT17}$ cells. To determine the potential tissue specificity of $\gamma \delta \mathrm{T} 17$ cells, we performed transcriptome analyses of $\gamma \delta \mathrm{T} 17$ cells from the spleen, small and large intestines by RNA sequencing (RNA-seq). Results showed distinct transcriptional signatures among splenic, small and large intestinal $\gamma \delta \mathrm{T} 17$ cells (Fig. $4 \mathrm{a}, \mathrm{b}$ ), suggesting a tissue imprinting on $\gamma \delta \mathrm{T} 17$ cell transcriptome. Of note, principal component analysis (PCA) indicated that the transcriptional signature of splenic $\gamma \delta \mathrm{T} 17$ cells was more distinct from those of small and large intestinal $\gamma \delta \mathrm{T} 17$ cells (Fig. $4 \mathrm{a}$ ). Next, we defined the tissuespecific gene (TSG) sets among splenic, small and large intestinal $\gamma \delta \mathrm{T} 17$ cells (criteria: $\mathrm{FPKM} \geq 4$, fold change $\geq 10, q \leq 0.05$ ). Comparing intestinal (including small and large intestines) and splenic $\gamma \delta$ T17 cells, a total of 163 TSGs (50 TSGs in the splenic $\gamma \delta \mathrm{T} 17$ cells vs. 113 TSGs in the intestinal $\gamma \delta \mathrm{T} 17$ cells) were identified (Fig. $4 \mathrm{~b}$ and Supplementary Table 1). Among spleen TSGs, S1pr1 that controls naïve T cell egress from lymph nodes, and genes involved in cell adhesion (e.g., Itgad, Vcam1, Fut7) were identified (Fig. 4b), suggesting a unique mechanism of regulation that involves migration and/or retaining $\gamma \delta \mathrm{T} 17$ cells in the spleen.

Several observations emerged after careful assessment of intestinal $\gamma \delta \mathrm{T} 17$ TSGs. Expression of aryl hydrocarbon receptor $(A h r)$, an environment sensor that is preferentially expressed in $\mathrm{CD}^{+} \mathrm{T}$ cells and ILCs in the gut compared with other tissues $^{32,33,49}$, was higher in gut $\gamma \delta T 17$ cells than spleen $\gamma \delta T 17$ cells (Fig. 4c). Accordingly, a group of genes (Ahrr, Asb2, Cd93, Cd160, Gem, Hic1, Il17a, Il22, Kit, Neurl3, Osgin1, Vps37b), all of which have been identified as Ahr direct targets in CD4 ${ }^{+} \mathrm{T}$ cells by ChIP-seq ${ }^{49}$, were also expressed substantially higher in the gut compared with the spleen (Fig. 4b, c). Higher expression of Ahr and c-Kit (encoded by Kit) in intestinal $\gamma \delta \mathrm{T} 17$ cells compared with splenic $\gamma \delta \mathrm{T} 17$ cells was observed at the protein level by FACS (Fig. 4d and Supplementary Fig. 5a, b). In addition, intestinal $\gamma \delta \mathrm{T} 17$ cells (especially the small intestinal $\gamma \delta \mathrm{T} 17$ cells) had higher IL-22 protein expression compared with splenic $\gamma \delta \mathrm{T} 17$ cells, even upon stimulation of IL- $1 \beta$ and IL-23 that could substantially enhance IL-22 expression by $\gamma \delta \mathrm{T} 17$ cells in all tissues (Fig. 4e and Supplementary Fig. 5c). Of note, genes in transforming growth factor beta (TGF- $\beta$ ) signaling pathway (Tgif1 and Thbs1 (refs. $\left.{ }^{50-52}\right)$ ) were also among the TSGs of intestinal $\gamma \delta \mathrm{T} 17$ cells (Fig. $4 \mathrm{~b}$ and Supplementary Fig. $5 \mathrm{~d}$ ), in line with the fact that TGF- $\beta$ is highly enriched in the gut ${ }^{53}$. Thus, these data suggested an adaptation to the gut milieu by $\gamma \delta \mathrm{T} 17$ cells through engagement of the Ahr pathway and TGF- $\beta$ pathway.

Gene Ontology (GO) analysis of 113 intestinal TSGs and 50 splenic TSGs further showed that gut $\gamma \delta$ T17 TSGs were more enriched in cell activation, and cytokine and inflammatory responses compared with splenic TSGs (Fig. 4f and Supplementary Fig. 5e). Consistently, T cell effectors (e.g., Il17a, Il17f, Il22, and Areg) and activation molecules (Bhlhe40, Egr1, Nr4a1, Nr4a2, and Nr4a3) were among TSGs of intestinal $\gamma \delta \mathrm{T} 17$ cells (Fig. $4 \mathrm{~b}$ and Supplementary Table 1$)^{54-58}$. In contrast to the distinct expression patterns of gut and spleen $\gamma \delta \mathrm{T} 17$ cells, comparing the small and large intestinal WT $\gamma \delta \mathrm{T} 17$ cells, a limited number of TSGs, 12 for small intestinal and 7 for large intestinal $\gamma \delta$ T17 cells, were identified (Supplementary Table 1). Together, these results suggested that intestinal $\gamma \delta \mathrm{T} 17$ cells adopt a unique gene signature with a more activated feature compared with splenic $\gamma \delta \mathrm{T} 17$ cells, consistent with the immunologically stimulating environment of the gut.

Tfam deficiency affects PLZF expression and $\gamma \delta \mathrm{T} 17$ cell proliferation. To determine the mechanisms by which Tfam deficiency affects the systemic $\gamma \delta \mathrm{T} 17$ cell maintenance, we performed transcriptome analyses by comparing Tfam-sufficient (Ctr) and -deficient $(\mathrm{KO}) \gamma \delta \mathrm{T} 17$ cells and defined differentially expressed genes (DEGs, FPKM $\geq 1$, fold change $\geq 1.5, q \leq 0.05$ ) in multiple tissues. A total of 265 splenic DEGs (75 up- and 190 downregulated genes), 467 small intestinal DEGs (224 up- and 243 down-regulated genes), and 596 large intestinal DEGs (193 upand 403 down-regulated genes) were identified in Tfam-deficient $\gamma \delta \mathrm{T} 17$ cells (Supplementary Fig. $5 \mathrm{f}-\mathrm{h}$ and Supplementary Tables 2-4)

Examination of 35 core DEGs that were shared among splenic, small, and large intestinal DEGs (Fig. $4 \mathrm{~g}$ ) indicated pathways that were compromised by Tfam deficiency. As expected, mitochondrial genes (mt-Co1, mt-Nd1, mt-Nd2, mt-Nd4, mt-Nd5, mtNd6, mt-Cytb) were down-regulated in Tfam-deficient $\gamma \delta \mathrm{T} 17$ cells in all tissues examined (Fig. 4h), consistent with the key role of Tfam in regulating mitochondrial gene transcription. We also noted an altered expression of genes involved in several fundamental biological processes, such as the actin cytoskeleton remodeling pathway for cell motility and growth and transcriptional regulation pathway for cell proliferation in Tfam-deficient $\gamma \delta \mathrm{T} 17$ cells. For example, a group of genes involved in small GTPase signaling or related to cytoskeleton regulation ( $P s d 2$, Arap3, Ablim3) ${ }^{59}$ was down-regulated in Tfam-deficient $\gamma \delta \mathrm{T} 17$ cells (Fig. 4h). Ptger4, which has been shown to suppress B cell proliferation $^{60}$, was increased, while Runx2, critical for osteoblast proliferation $^{61}$, was markedly decreased in Tfam-deficient $\gamma \delta \mathrm{T} 17$ cells (Fig. 4h).

Zbtb16 showed a consistent decrease in splenic, small and large intestinal Tfam-deficient $\gamma \delta \mathrm{T} 17$ cells compared with littermate control $\gamma \delta \mathrm{T} 17$ cells (Fig. $4 \mathrm{~h}$ ). Since promyelocytic leukemia zincfinger protein (PLZF, encoded by Zbtb16) has been shown to play a key role in promoting $\gamma \delta \mathrm{T} 17$ cell development and proliferation $^{45}$. We further determined its protein expression by flow cytometry. PLZF expression was decreased in both splenic and intestinal Tfam-deficient $\gamma \delta T 17$ cells (Fig. 4i). Consistent with altered expression of multiple genes involved in cell proliferation, Ki-67 staining and BrdU incorporation were reduced in Tfam-deficient splenic and gut $\gamma \delta \mathrm{T} 17$ cells (Fig. 4j and Supplementary Fig. 5i). However, BrdU-positive cells were similar between control and Tfam-deficient ILC3s at 3-week-old age (Supplementary Fig. 5j). Furthermore, BrdU incorporation in ILC3s was not decreased upon deletion of Tfam in mice at 8week-old age, when ILC3s showed a significant reduction (Supplementary Fig. 5j and Fig. 2c), suggesting that a yet-to-be determined mechanism other than proliferation defect may lead to the decrease of ILC3s in Tfam ${ }^{f l / f l}$ Rorc-cre mice. No significant difference in apoptosis was observed upon deletion of Tfam in $\gamma \delta \mathrm{T} 17$ cells (Supplementary Fig. 5k, l). Together, we conclude that Tfam deficiency in $\gamma \delta \mathrm{T} 17$ cells alters a selected set of core gene expression, resulting in defective cell proliferation.

Tfam deficiency causes transcriptomic changes of small intestine tissue remodeling. To determine potential mechanisms underlying the lengthened small intestine in Tfam ${ }^{f l f l}$ Rorc-cre mice, we performed small intestine tissue gene expression profiling by RNA-seq. A total of 1838 DEGs (FPKM $\geq 1$, fold change $\geq 1.5, q \leq$ $0.05)$ were identified, with 1217 genes up-regulated and 621 genes down-regulated in small intestine tissue of $\mathrm{Tfam}^{\mathrm{fl} / \mathrm{fl} \text { Rorc-cre mice }}$ 


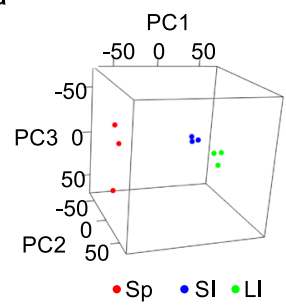

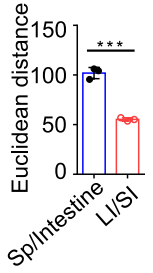

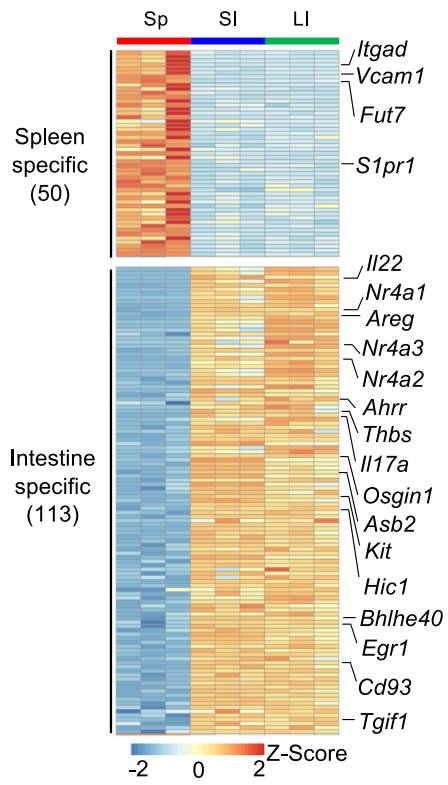

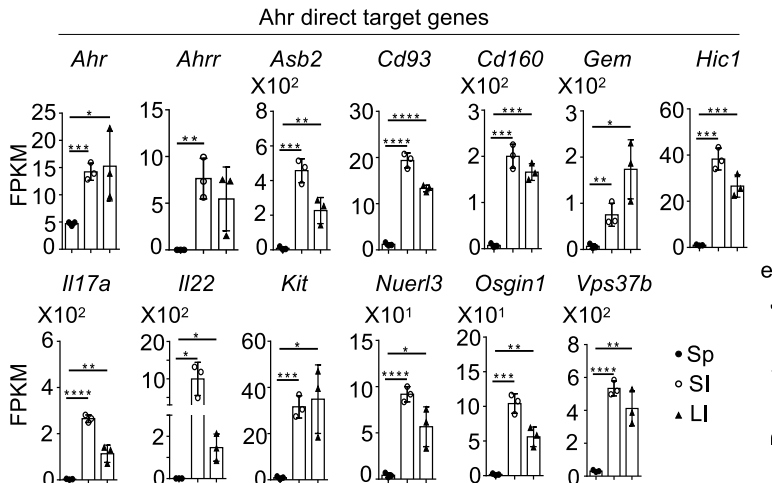

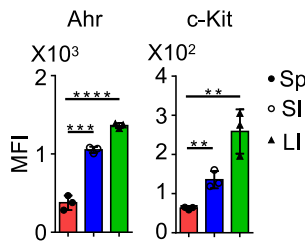

$\mathrm{f}$

\begin{tabular}{|c|c|}
\hline Gene Set Name & q-value \\
\hline Response to lipid & $5.72 \mathrm{E}-15$ \\
\hline Cell activation & $9.25 \mathrm{E}-14$ \\
\hline $\begin{array}{l}\text { Response to oxygen } \\
\text { containing compound }\end{array}$ & $9.25 \mathrm{E}-14$ \\
\hline $\begin{array}{l}\text { Regulation of cell population } \\
\text { proliferation }\end{array}$ & $9.25 \mathrm{E}-14$ \\
\hline $\begin{array}{l}\text { Regulation of immune } \\
\text { system process }\end{array}$ & $3.11 \mathrm{E}-13$ \\
\hline Response to cytokine & $5.74 \mathrm{E}-13$ \\
\hline $\begin{array}{l}\text { Circulatory system } \\
\text { development }\end{array}$ & $2.58 \mathrm{E}-12$ \\
\hline $\begin{array}{l}\text { Response to steroid } \\
\text { hormone }\end{array}$ & $1.31 \mathrm{E}-11$ \\
\hline $\begin{array}{l}\text { Cellular response to } \\
\text { endogenous stimulus }\end{array}$ & $2.70 \mathrm{E}-11$ \\
\hline Inflammatory response & $3.11 \mathrm{E}-11$ \\
\hline
\end{tabular}<smiles>C1CCCC1</smiles>

g

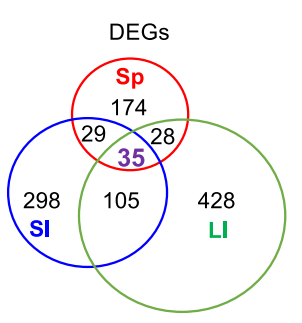

i
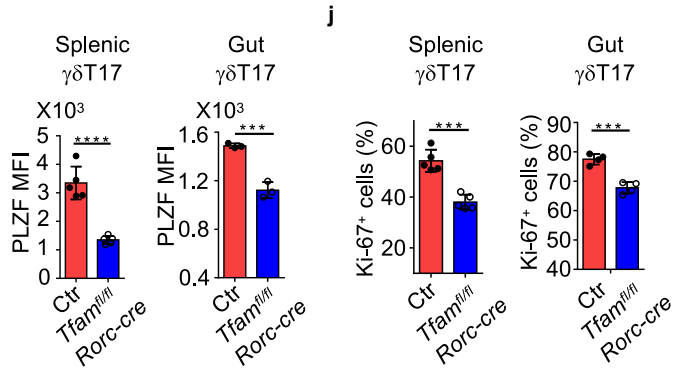

h

$\frac{\mathrm{Sp}}{\mathrm{Ctr} K \mathrm{SI}} \frac{\mathrm{SI}}{\operatorname{Ctr} \mathrm{KO}}$
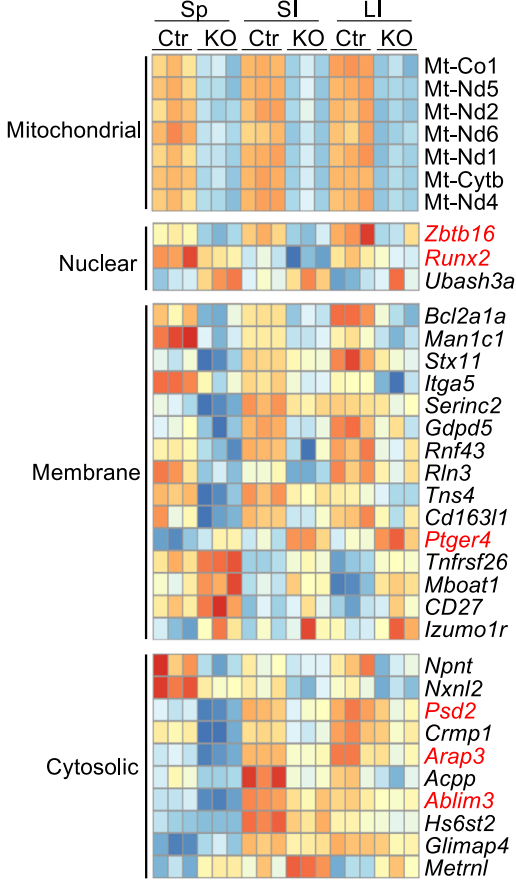

$-2 \quad 0 \quad 2^{\text {Z-Score }}$

Fig. 4 Gene profiling reveals tissue-specific transcriptomic signature of $\boldsymbol{\gamma} \boldsymbol{\delta} \mathbf{T 1 7}$ cells. a Left panel, principal component analysis (PCA) plot of the RNA-seq of Tfam-sufficient splenic (Sp), small intestinal (SI), and large intestinal (LI) $\gamma \delta T 17$ cells from 3-week-old ( $n=3$ for each group) mice. $\gamma \delta T 17$ cells of each sample were sorted from an individual mouse. Right panel, Euclidean distance comparison of the transcriptome of each splenic $\gamma \delta T 17$ cell sample and the mean intestine centroid vs. the mean small intestine centroid to each large intestinal $\gamma \delta T 17$ cell sample $\left(n=3\right.$ for each group) ( $\left.{ }^{\star \star \star} P=0.0002\right)$.

b Heatmap of tissue-specific genes (TSGs) identified by the RNA-seq in Sp, SI, and LI $\gamma \delta T 17$ cells. Genes were ranked in a descending order based on the fold changes of expression (Sp/[SI and LI average mean]; [SI and LI average mean]/Sp). c RNA-seq FPKM values of Ahr direct target genes of Sp, SI, and LI $\gamma \delta \mathrm{T} 17$ cells (mean \pm SD) $\left(n=3\right.$ for each group) (Sp vs. Sl: Ahr, ${ }^{\star \star \star} P=0.0005, A h r r,{ }^{\star \star} P=0.0037,{ }^{\star}$ ssb2, ${ }^{\star \star \star \star} P=0.0004, C d 93,{ }^{\star \star \star \star} P<0.0001, C d 160,{ }^{\star \star \star \star} P=$ 0.0002, Gem, ${ }^{\star \star} P=0.0096$, Hicl, ${ }^{\star \star \star} P=0.0002, I 117 a,{ }^{\star \star \star \star} P<0.0001, I 122,{ }^{\star} P=0.0180$, Kit, ${ }^{\star \star \star} P=0.0004$, Nuerl3, ${ }^{\star \star \star \star} P<0.0001,0$ sgin1, ${ }^{\star \star \star} P=0.0002$,

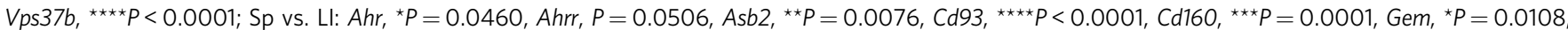
Hic1, ${ }^{\star \star \star} P=0.0008, I 117 a,{ }^{\star}{ }^{\star} P=0.0071, I 122,{ }^{\star} P=0.0171$, Kit, ${ }^{\star} P=0.0166$, Nuerl3, ${ }^{\star} P=0.0137$, Osgin1, $\left.{ }^{\star \star} P=0.0027, V p s 37 b,{ }^{\star} P=0.0034\right)$. FPKM,

fragments per kilobase of exon model per million mapped fragments. d Ahr and c-Kit expression in Sp, SI, and LI $\gamma \delta \mathrm{T} 17$ cells by flow cytometry $(n=4$ for each group) (Sp vs. Sl: Ahr, ${ }^{\star \star \star} P=0.0003, c-K i t,{ }^{\star \star} P=0.0049$; Sp vs. Ll: Ahr, ${ }^{\star \star \star \star} P<0.0001, c-K i t,{ }^{\star \star} P=0.0039$ ). Compiled data from one experiment. e Percentages of IL-22+ cells in Sp, SI, and LI $\gamma \delta T 17$ cells by flow cytometry ( $n=4$ for each group) (Sp vs. SI: PMA + lono, ${ }^{\star \star} P=0.0046, I L-1 \beta+I L-23,{ }^{\star \star \star \star} P$ $<0.0001$; Sp vs. LI: PMA + lono, $\left.{ }^{\star \star} P=0.0021, \mathrm{IL}-1 \beta+\mathrm{IL}-23,{ }^{\star \star} P=0.0027\right)$. Cells were stimulated with or without PMA (20 ng/ml) plus ionomycin (lono) $(1 \mu \mathrm{g} / \mathrm{ml})$ but with IL-1 $\beta(10 \mathrm{ng} / \mathrm{ml})$ plus IL-23 $(10 \mathrm{ng} / \mathrm{ml})$ for $6 \mathrm{~h}$. Compiled data from one experiment. $\mathbf{f}$ GO analysis of the 113 TSGs in $\gamma \delta T 17$ cells. $\mathbf{g}$ Pie graph of differentially expressed genes (DEGs) between Ctr and Tfam-deficient $\gamma \delta \mathrm{T} 17$ cells from Sp, SI, and LI. $\mathbf{h}$ Heatmap of the 35 core Tfam-regulated

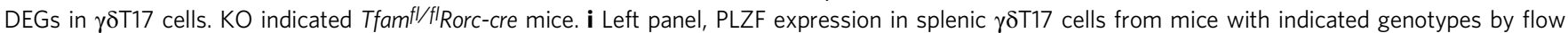
cytometry ( $n=5$ for each group) (splenic, ${ }^{\star \star \star \star} P<0.0001$; gut, ${ }^{\star \star \star} P=0.0008$ ). Compiled data from two independent experiments. Right panel, PLZF expression in gut $\gamma \delta \mathrm{T} 17$ cells from mice with indicated genotypes by flow cytometry ( $n=3$ for each group). Compiled data from one experiment. $\mathbf{j}$ Left panel, Ki-67 expression in splenic $\gamma \delta T 17$ cells from 3-week-old mice with indicated genotypes by flow cytometry ( $n=5$ for each group) (spleen, ${ }^{\star \star \star} P=0.0001$; gut, $\left.{ }^{\star \star \star} P=0.0003\right)$. Compiled data from two independent experiments. Right panel, Ki-67 expression in gut $\gamma \delta T 17$ cells from 1-week-old mice with indicated genotypes by flow cytometry ( $n=4$ for each group). Compiled data from one experiment. Ctr included Tfam fl/fl, Tfam $+/+$ Rorc-Cre, and Tfam ${ }^{f / /}+$ Rorc-cre mice in $\mathbf{g}$-j. Data are shown as mean $\pm S D$ in $\mathbf{a}, \mathbf{c}-\mathbf{e}, \mathbf{i}, \mathbf{j}$. 


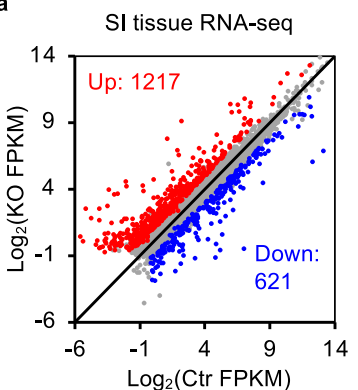

e

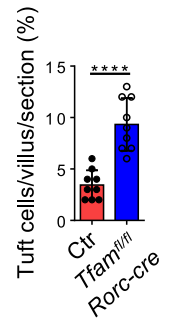

i

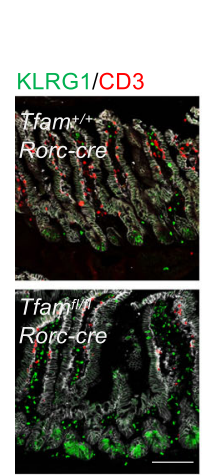

f

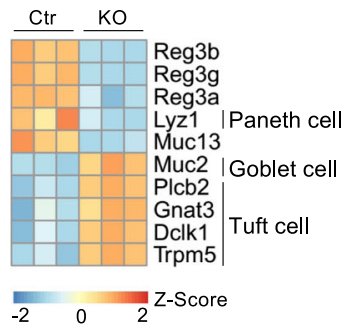

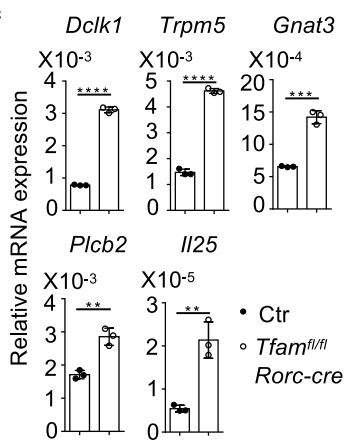

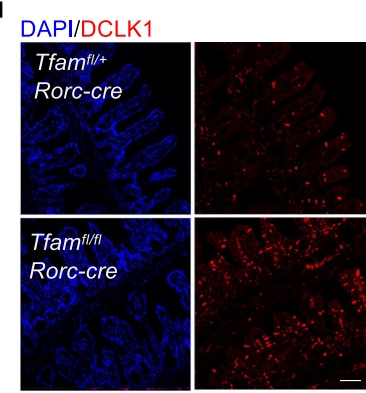

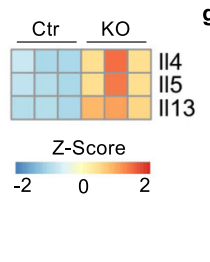

g
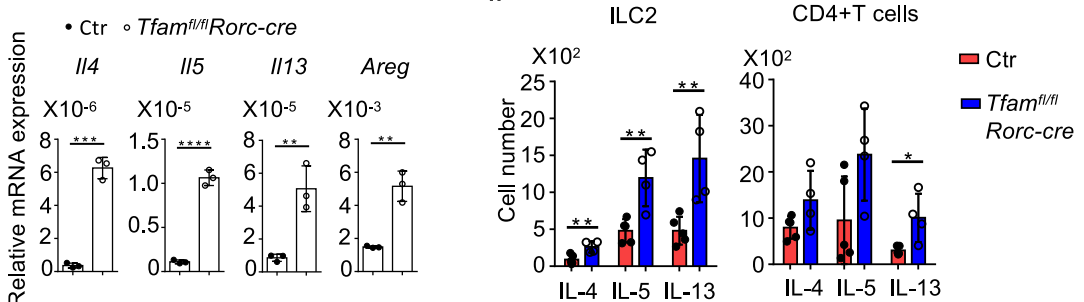

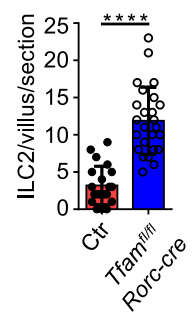

$\mathbf{k}$

- Ctr

-Tfam ${ }^{\text {fl/fI} R o r c-c r e ~}$

- Ctr + anti-Thy 1.2

- Tfam ${ }^{\text {fl/fl} R o r c-c r e}$

+ anti-Thy 1.2

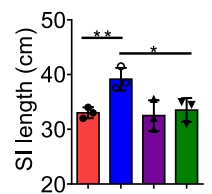

I

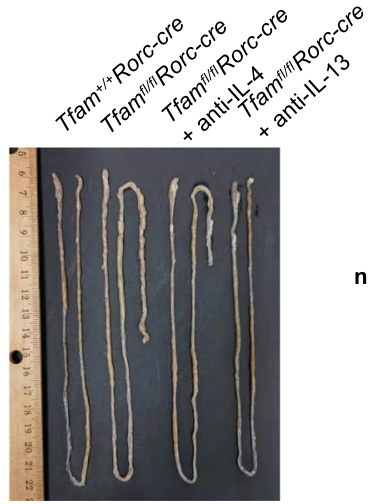

m
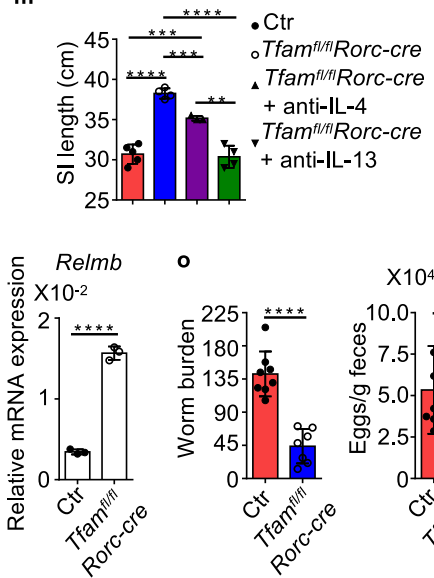

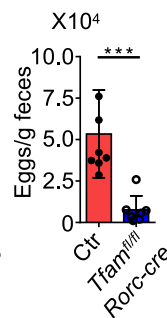

compared with control mice (Fig. 5a, Supplementary Fig. 6a and Supplementary Table 5). Among them, genes involved in insulin growth factor (Igf) signaling (i.e., Igf1, Igf2, Igflr, $\operatorname{Igf} 2 r$, Igfbp2, Igfbp4, Igfbp6, and Igfbp7), which have been shown to promote intestine epithelial proliferation ${ }^{62}$, were significantly up-regulated (Supplementary Fig. $6 \mathrm{~b}, \mathrm{c}$ ), and thus potentially contributed to the increased

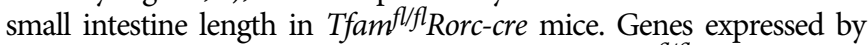
secretory epithelial cells were also changed in Tfam ${ }^{f l / f l}$ Rorc-cre mice. For example, Reg3a, Reg3b, Reg3g, target genes of IL-22 (ref. ${ }^{63}$ ), were down-regulated in small intestinal tissue of Tfam ${ }^{f l / f l}$ Rorc-cre mice compared with littermate control mice (Fig. 5b), consistent with the reduction of IL-22-producing cells (ILC3s and $\gamma \delta T 17$ cells). Lyz1, which encodes the Paneth cell-specific lysozyme, was also decreased in the small intestine of Tfam ${ }^{f / f f}$ Rorc-cre mice (Fig. 5b). In contrast, $M u c 2$, which is expressed by goblet cells, was increased in the small intestine of Tfam fl/flRorc-cre mice (Fig. 5b). Consistently, periodic acid-Schiff (PAS) staining further indicated an increase of goblet cells in the small intestine of Tfam fl/flRorc-cre mice (Supplementary Fig. 6d). Of note, several genes that are highly expressed by tuft cells (e.g., Dclk1, Trpm5, Gnat3, Plcb2, and Il25) were up-regulated in the small intestine of Tfam fl/fl Rorc-cre mice (Fig. 5b, c), suggesting an increase of tuft cells in the small intestine of Tfam fl/fl Rorc-cre mice. Tuft cell enhancement was further validated by confocal microscopy analysis of DCLK1 expression (Fig. 5d, e). Together, these results demonstrated that genetic ablation of Tfam in ROR $\gamma \mathrm{t}^{+}$lymphocytes causes small intestine tissue transcriptomic changes associated with increased tissue remodeling.

Tfam deficiency in ROR $\gamma \mathrm{t}^{+}$lymphocytes enhance type 2 immunity in the small intestine. A recent study showed that increased tuft cell-ILC2 circuit drives small intestine lengthening in mice deficient in Tnfaip 3 (encodes A20), a negative regulator of $\mathrm{ILC}^{38}{ }^{38}$, phenocopying Tfam ${ }^{f l / f l}$ Rorc-cre mice. Indeed, a marked enhancement of type 2 immune genes (Il4, Il5, Ill3, and Areg) was observed in the small intestine tissues of Tfam ${ }^{f l / f l}$ Rorc-cre mice compared with littermate control mice (Fig. 5f, g). Accordingly, type 2 immune cells, especially ILC2s, were increased in Tfam fl/fl Rorc-cre mice (Fig. $5 \mathrm{~h}$ and Supplementary Fig. 6e). Confocal staining further confirmed a significant increase of ILC2s in the small intestine lamina propria of Tfam ${ }^{f / f l}$ Rorc-cre mice compared with littermate control mice (Fig. 5i, j). AntiThy1.2 neutralizing antibody treatment, which depletes Thy $1.2^{+}$ lymphocytes including ILC2s, fully restored the small intestine length of Tfam $f^{f / f l}$ Rorc-cre mice to the level of littermate control mice (Fig. 5k). In addition, in vivo neutralizing type 2 cytokines (IL-4 or IL-13) either partially or completely restored the small intestine length of Tfam fllfl Rorc-cre mice (Fig. 5l, m). 
Fig. 5 ROR $\gamma \mathbf{t}$-specific ablation of Tfam leads to small intestine tissue remodeling with enhanced tuft cell-ILC2 circuit. Ctr included Tfam $+/+R o r c-c r e$ and $\operatorname{Tfam}^{f l /}+$ Rorc-cre mice in $\mathbf{a}, \mathbf{b}, \mathbf{f}$. KO indicated Tfam ${ }^{f / / f l}$ Rorc-cre mice. $\mathbf{a}$ Differential gene expression by RNA-seq analysis of small intestine tissues of Ctr ( $n=$ 3 ) and KO mice $(n=3)$ at 12 -week-old age (fold change $\geq 1.5, q$ value $\leq 0.05$ ). b Heatmap of indicated gene expression from RNA-seq analysis of small intestine tissues of $\mathrm{Ctr}$ and $\mathrm{KO}$ mice. Each sample represented one individual mouse. c Analysis of tuft cell-related gene expression by qRT-PCR in the small intestine tissues of 12-week-old Ctr and Tfam ${ }^{f / f l}$ Rorc-cre mice $(n=3)\left(D c l k 1,{ }^{\star \star \star \star} P<0.0001 ; \operatorname{Trpm5}\right.$, ${ }^{\star \star \star \star} P<0.0001 ; G n a t 3,{ }^{\star \star \star \star} P=0.0002 ; P l c b 2$,

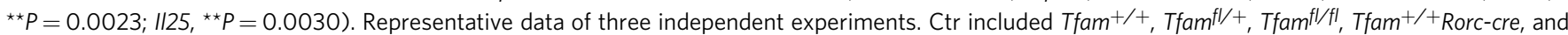
Tfam ${ }^{f l /}+$ Rorc-cre mice in c, e, g-o. d Confocal analysis of tuft cells by DCLK1 staining in the small intestine (ileum) of 12-week-old mice with indicated genotypes. Red, DCLK1 staining. Blue, DAPI nuclear staining. Scale bar, $200 \mu \mathrm{m}$. Representative data from three independent experiments. e Quantification of tuft cells $\left(\mathrm{DCLK} 1^{+}\right)$in each small intestine villus viewed by confocal microscopy ( $n=9$ villi for each group) ( $\left.{ }^{\star \star \star \star} P<0.0001\right)$. Compiled data from two independent experiments. $\mathbf{f}$ Heatmap of indicated gene expression from RNA-seq analysis of small intestine tissues of $\mathrm{Ctr}$ and $\mathrm{KO}$ mice. $\mathbf{g}$ Analysis of $I / 4$, II5, II13, and Areg expression by qRT-PCR in small intestine tissues of 12-week-old Ctr and Tfam ${ }^{f / f f}$ Rorc-cre mice $(n=3)\left(I / 4,{ }^{\star \star \star} P=0.0001 ; \| 15\right.$, ${ }^{\star \star \star \star} P<$ $0.0001 ; \| 113,{ }^{\star \star} P=0.0066$; Areg, $\left.{ }^{\star \star} P=0.0023\right)$. Representative data of three independent experiments. $\mathbf{h} \mathrm{IL}-4, \mathrm{IL}-5$, and IL-13 expression in ILC2s or CD4+ T cells by flow cytometry from the small intestine draining lymph nodes (siLN) of Ctr $(n=5)$ and Tfamfl/fl/Rorc-cre $(n=4)$ mice at 12-week-old age (ILC2: $\mathrm{IL}-4,{ }^{\star \star} P=0.0082 ; \mathrm{IL}-5,{ }^{\star \star} P=0.0064 ; \mathrm{IL}-13,{ }^{\star \star} P=0.0097 ; \mathrm{CD} 4+\mathrm{T}$ cells: IL-4, $\left.P=0.0929 ; \mathrm{IL}-5, P=0.0652 ; \mathrm{IL}-13,{ }^{\star} P=0.0194\right)$. Compiled data from two independent experiments. i Confocal analysis of ILC2s $\left(\mathrm{CD}^{-} \mathrm{KLRG1}^{+}\right)$in the small intestine (ileum) of 12-week-old mice with indicated genotypes. Red, CD3 staining. Green, KLRG1 staining. White, EpCAM staining. Scale bar, $200 \mu \mathrm{m}$. Representative data of three independent experiments. $\mathbf{j}$ Quantification of ILC2s $\left(\mathrm{CD}^{-} \mathrm{KLRG1}^{+}\right)$in each small intestine villus viewed by confocal microscopy $\left({ }^{\star \star \star \star} P<0.0001\right)$. Ctr, $n=21, T$ ffam ${ }^{f l / f l}$ Rorc-cre, $n=22$. Compiled data from two independent experiments. $\mathbf{k}$ Small intestine length in Ctr or Tfam ${ }^{f / f l}$ Rorc-cre mice treated with anti-Thy 1.2 neutralizing antibody for 3 weeks $(n=3$ for each group) (Ctr vs. Tfam ${ }^{f l / f l}$ Rorc-cre, ${ }^{\star \star} P=0.0098$; Tfam ${ }^{f / / f l}$ Rorc-cre vs. Tfam ${ }^{\text {fl/fl}}$ Rorc-cre + anti-Thy1.2, ${ }^{\star} P=0.0312$ ). Compiled data from two independent experiments. I Picture of small intestines in mice of indicated genotypes treated with anti-IL-4 antibody (100 $\mu \mathrm{g} / \mathrm{mouse})$ or anti-IL-13 antibody ( $50 \mu \mathrm{g} /$ mouse) twice a week from 6-week-old age for 3 weeks by intraperitoneal cavity injection. Representative data of two independent experiments. m Small intestine length. Compiled data from two independent experiments (Ctr vs. Tfam ${ }^{f l / f l}$ Rorc-cre, ${ }^{\star \star \star \star} P<0.0001 ; \mathrm{Ctr}$ vs. Tfam fl/flRorc-cre + anti-IL-4, ${ }^{\star \star \star} P=0.0009 ;$ Tfam ${ }^{f l / f l}$ Rorc-cre vs. Tfam ${ }^{f l / f l}$ Rorc-cre + anti-IL-4, ${ }^{\star \star \star} P=0.0006 ;$ Tfam ${ }^{f l / f l}$ Rorc-cre vs. Tfam ${ }^{f l / f l}$ Rorc-cre + anti-IL-13, ${ }^{\star \star \star \star *} P<0.0001 ;$ Tfam ${ }^{f l}$ ${ }^{f l}$ Rorc-cre + anti-IL-4 vs. Tfam ${ }^{f / / f l}$ Rorc-cre + anti-IL-13, $\left.{ }^{\star \star} P=0.0022\right) . n=5$ for Ctr, $n=4$ for Tfam ${ }^{f / f l}$ Rorc-cre mice; $n=3$ for Tfam ${ }^{f l / f l}$ Rorc-cre mice treated with anti-IL-4; $n=4$ for Tfam ${ }^{\text {fl/fl} R o r c-c r e ~ m i c e ~ t r e a t e d ~ w i t h ~ a n t i-I L-13 . ~} \mathbf{n}$ Analysis of Relmb expression by qRT-PCR in the small intestine tissues of 12-weekold Ctr and Tfam ${ }^{f l / f l}$ Rorc-cre mice $(n=3)$ mice at 14 days after Hpb infection ( $\left.\star \star \star \star P<0.0001\right)$. Representative data of three independent experiments. 0 Left panel, $\mathrm{Hpb}$ worm burden in small intestine lumen of $\mathrm{Ctr}(n=8)$ and $T f a m^{f l / f l}$ Rorc-cre mice $(n=7)$ at 14 days after Hpb infection ( $\left.{ }^{\star \star \star \star *} P<0.0001\right)$. Right panel, $\mathrm{Hpb}$ egg counts per gram feces in $\operatorname{Ctr}(n=8)$ and Tfam fl/flRorc-cre mice $(n=7)$ mice at 14 days after Hpb infection ( $\left.{ }^{\star \star \star} P=0.0008\right)$. Compiled data

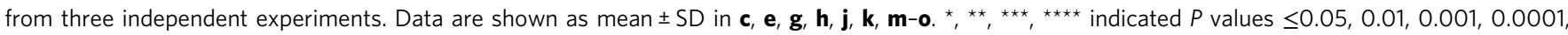
respectively.

Together, these data suggest that Tfam in $\gamma \delta \mathrm{T} 17$ cells regulates small intestine tissue remodeling through a type 2 immunitydependent manner under steady-state condition.

It was reported that the regulation of small intestine length by tuft-ILC2 cell circuit was dependent on the Tritrichomonas spp. (a protozoa sensitive to antibiotics metronidazole (MNZ) treatment $)^{38}$. Intriguingly, the amounts of Tritrichomonas spp. had no difference or were even decreased without statistical significance in Tfam ${ }^{f l f l}$ Rorc-cre mice at various ages, including when the mice developed lengthened small intestine (Supplementary Fig. 6f). However, consistent with the literature ${ }^{38}$, MNZ treatment reduced Tritricomonas spp. and abrogated the phenotypes of increased small intestine length (Supplementary Fig. 6g-i). These data suggested that the MNZ-sensitive microbiome and/or eukaryome may be responsible for the intestinal phenotypes observed in Tfam ${ }^{f l / f l}$ Rorc-cre mice.

Enhanced type 2 immunity in the small intestine of Tfam ${ }^{\text {fl }}$ ${ }^{f} l_{\text {Rorc-cre mice }}$ was also evident during infection. Upon infection of Heligmosomoides polygyrus bakeri (Hpb), increased ILC2s and Th2 cells in the siLN of Tfam ${ }^{\text {flfl }}$ Rorc-cre mice were observed compared with littermate control mice (Supplementary Fig. 6j). There was higher Relmb expression (encoding resistin-like molecule $\beta$, a protein involved in protection against infection by parasitic helminth ${ }^{32}$ ) in the small intestine of Tfam fl/fl/Rorc-cre mice after $H p b$ infection (Fig. 5n). As a result, Tfam ${ }^{f l / f l}$ Rorc-cre mice had lower worm burden in the small intestine and fewer egg counts in feces compared to littermate control mice (Fig. 5o). Together, these results demonstrate that Tfam ${ }^{f l f l}$ Rorc-cre mice had enhanced type 2 immune responses (e.g., ILC2s and Th2 cells) that lead to better anti-helminth immunity.

IL-22 suppresses IL-13-induced tuft cell differentiation. Type 2 cytokine IL-13 has been shown to promote tuft cell differentiation, highlighting the importance of tuft cell-ILC2 circuit in small intestine tissue remodeling ${ }^{35-37}$. As gut $\gamma \delta \mathrm{T} 17$ cells produce large amounts of IL-22 (ref. ${ }^{64}$ ), we hypothesized that IL-22 may directly inhibit the IL-13-induced tuft cell differentiation. As expected, IL-13 treatment enhanced tuft cell differentiation indicated by induction of Dclk1 and Trpm5 expression in the in vitro enteroid culture model (Fig. 6a and Supplementary Fig. 7). The increase of DCLK1 expression by IL13 treatment was further corroborated at the protein level by flow cytometry and confocal microscopy analyses (Fig. 6b-d). Notably, IL-22 but not IL-17A, both of which are highly expressed by $\gamma \delta \mathrm{T} 17$ cells, decreased DCLK1 expression induced by IL-13 (Fig. 6b-d), suggesting that IL-22 can inhibit IL-13-induced tuft cell differentiation in vitro. Consistently, Il22 knockout mice (Il22 $\mathrm{Cre} / \mathrm{Cre}$ knockout/in mice) showed longer small intestine length compared to their control littermates (Il22 $\mathrm{Cre} /+)$ (Fig. 6e). Significant enhancement of ILC2s but not Th2 cells together with increased tuft cell gene expression (i.e., Dck1, Trpm5, Gnat3, and Il25) were observed in the small intestine of Il22 knockout mice (Fig. 6f, g). More importantly, overexpression of IL-22 in vivo in Tfam flfll Rorc-cre mice by hydrodynamic injection reduced the expression of tuft cell and type 2 immune genes and accordingly restored the small intestine length (Fig. 6h, i). Together, these results suggest that the phenotypes of small intestine tissue remodeling upon ablation of Tfam in $\mathrm{ROR}_{\mathrm{ft}}{ }^{+}$lymphocytes are at least in part due to lack of IL-22, a cytokine that suppresses the intestinal tuft cell-ILC2 circuit.

Tfam deletion in ROR $\gamma \mathrm{t}^{+}$lymphocytes lead to global metabolomic changes in the small intestine. Both GO and KEGG analyses of small intestine tissue RNA-seq data showed enrichment of DEGs associated with metabolism (e.g., small-molecule metabolic process, amino acid and lipid metabolic processes, and 


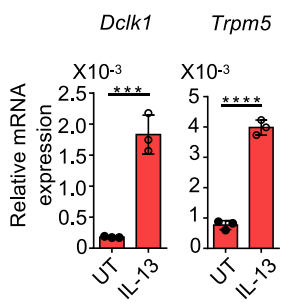

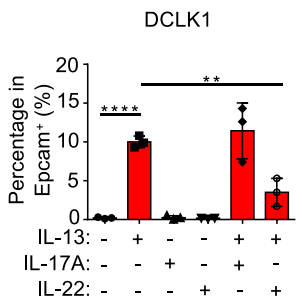

d

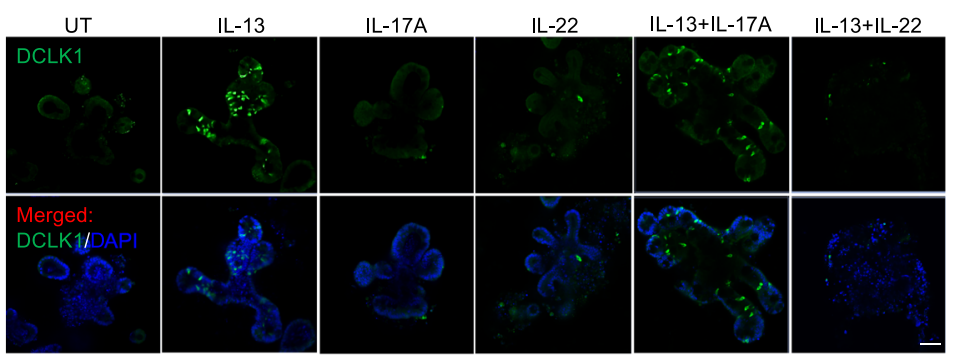

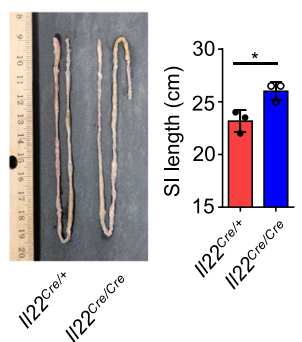

i
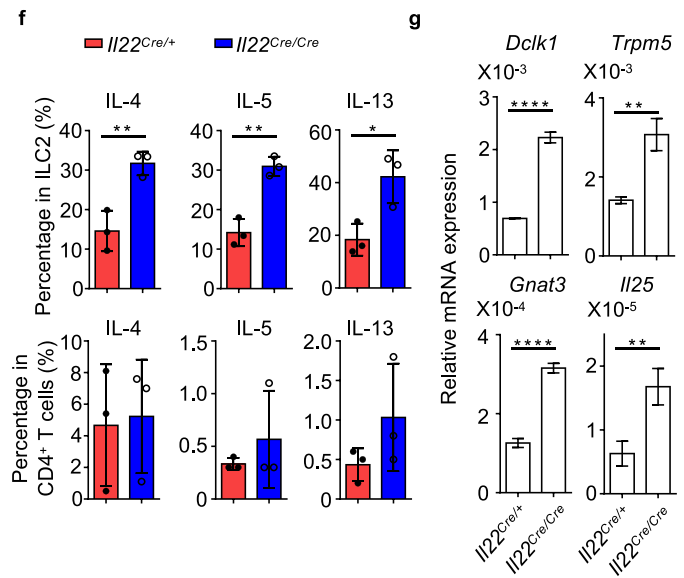

h

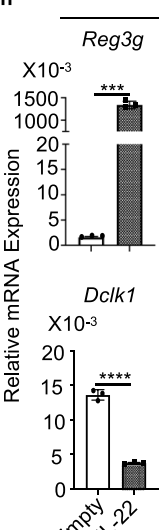

Tfam fl/fiRorc-cre

$\times 10^{-5}$

${ }^{110^{-5}}$

${\mathrm{X} 10^{-6}}^{1113}$
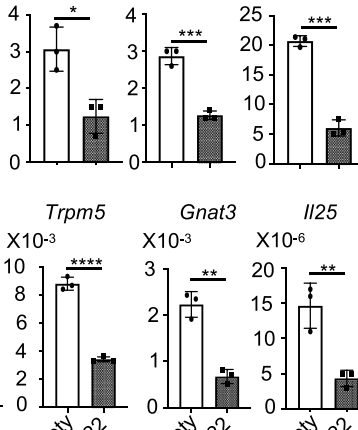

$\mathrm{X}^{110^{-6}}$

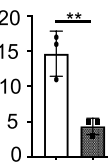

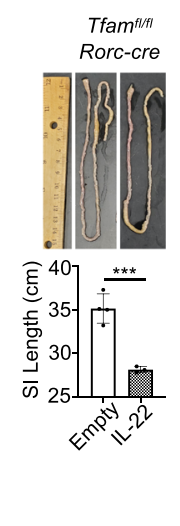

$2 v^{2}$

<it

$x^{2} v^{2}$

$v^{n^{2}+v^{2}}$

Fig. 6 IL-22 suppresses IL-13-induced tuft cell differentiation. a Analysis of Dclk7 and Trpm5 expression by qRT-PCR in enteroid culture ( $n=3$ ) (mean \pm SD) $\left(D c l k 1,{ }^{\star \star \star} P=0.0008 ; \operatorname{Trpm5},{ }^{\star \star \star \star \star} P<0.0001\right)$. Representative data of three independent experiments. b DCLK1 expression in enteroid culture with indicated treatment (IL-13 $(50 \mathrm{ng} / \mathrm{ml})$, IL-17A $(100 \mathrm{ng} / \mathrm{ml})$, and/or IL-22 $(5 \mathrm{ng} / \mathrm{ml}))$ measured by flow cytometry. Representative data of two independent experiments. c Percentages of DCLK1 ${ }^{+}$cells in EpCAM ${ }^{+}$cells (mean \pm SD) $(n=3)$ (none vs. IL-13, ${ }^{\star \star \star \star *} P<0.0001$; IL-13 vs. IL-13 + IL-22, $\left.{ }^{\star \star P} P=0.0045\right)$. Compiled data from one experiment. $\mathbf{d}$ Confocal analysis of DCLK1 expression in enteroid culture with indicated treatment. Representative data of two independent experiments. Green, DCLK1. Blue, DAPI. Scale bar: $50 \mu \mathrm{m}$. e Left panel, picture of the small intestine of 8-week-old littermate $I 122^{C} \mathrm{Cre} /+$ and $I 122^{\mathrm{Cre} / \mathrm{Cre}} \mathrm{mice}\left({ }^{\star} P=0.0223\right)$. Representative data of two independent experiments. Right panel, small intestine length in mice with indicated genotypes $(n=3)$. Compiled data from two independent experiments. $\mathbf{f I L}-4, \mathrm{IL}-5$, and IL-13 expression in ILC2s or CD4 ${ }^{+}$T cells by flow cytometry from the small intestine of 8-week-old II22Cre/ + and II22 Cre/Cre mice $(n=3)$ (ILC2: IL-4, ${ }^{\star \star} P=0.0076 ; \mathrm{IL}-5,{ }^{\star}{ }^{\star} P=0.0024 ; \mathrm{IL}-13,{ }^{\star} P=0.0245 ; \mathrm{CD} 4+\mathrm{T}$ : IL-4, $\left.P=0.8613 ; \mathrm{IL}-5, P=0.4343 ; \mathrm{IL}-13, P=0.2181\right)$. Compiled data from two independent experiments. $\mathbf{g}$ Analysis of Dclk1, Trpm5, Gnat3, and II25 expression by qRT-PCR in small intestine tissues of 8-week-old II22Cre/+ and $1122^{\mathrm{Cre} / \mathrm{Cre}}$ mice $(n=3)\left(D \mathrm{clk1},{ }^{\star \star \star \star \star} P<0.0001 ; \operatorname{Trpm5},{ }^{\star \star} P=0.0023 ;\right.$ Gnat3, $\left.{ }^{\star \star \star \star} P<0.0001 ; 1125,{ }^{\star \star} P=0.0062\right)$. Representative data of two independent experiments. $\mathbf{h}, \mathbf{i}$ Tfam ${ }^{f / / f l}$ Rorc-cre mice at the age of 6 weeks old received hydrodynamic tail vein injection of either empty or IL-22 vectors. Mice were sacrificed at 10 weeks of age and small intestine tissues were harvested. $\mathbf{h}$ qRT-PCR gene expression analysis of small intestine tissue IL-22-target gene Reg3g, type 2 cytokine genes II4, II5, and II13, and tuft cell-associated genes Dclk1, Trpm5, Gnat3, and II25 $(n=3)\left(\operatorname{Reg} 3 g,{ }^{\star \star \star} P=0.0001 ;\left\|4,{ }^{\star} P=0.0139 ;\right\| 15,{ }^{\star \star \star} P=0.0004 ; \| 13\right.$, ${ }^{\star \star \star} P=0.0001 ; D c l k 1,{ }^{\star \star \star \star} P<0.0001 ; \operatorname{Trpm} 5,{ }^{\star \star \star \star \star} P<0.0001$; Gnat3, $\left.{ }^{\star \star} P=0.0011 ; 1125,{ }^{\star \star} P=0.0063\right)$. Representative data of three independent experiments. i Top panel, picture of the small intestine length. Bottom panel, quantification of the small intestine length ( $n=4$ for empty group and $n=3$ for IL-22 treatment group) ( $\left.{ }^{\star \star \star} P=0.0009\right)$. Compiled data from one experiment. Data are shown as mean $\pm S D$ in $\mathbf{a}, \mathbf{c}, \mathbf{e}-\mathbf{i}$.

organic acid metabolic process) (Supplementary Fig. 8a, b). The dysregulated gene expression in metabolic pathways prompted us to directly assess the small intestine tissue metabolic changes in $T$ Tam $^{\text {fllfl }}$ Rorc-cre mice by global metabolome analysis.

PCA showed distinct metabolic profiles between the small intestine tissues of littermate control and Tfam ${ }^{\text {fl/fl }}$ Rorc-cre mice (Fig. 7a). A total of 42 annotated metabolites (among a total of 1498 detected metabolites) were identified as differentially regulated between the small intestine tissues of littermate control and Tfam ${ }^{f l f l}$ Rorc-cre mice (fold change $\geq 2, P \leq 0.05$ ) (Fig. $7 \mathrm{~b}$ and Supplementary Fig. 8c). These metabolites could be categorized into several pathways such as bile acid metabolism, glutathione metabolism, and amino acid metabolism (Fig. 7b). Of note, multiple forms of bile acids were markedly reduced in the small intestine tissues of Tfam ${ }^{f l f l}$ Rorc-cre mice (Fig. $7 \mathrm{~b}$ and Supplementary Fig. 8c, d). Since bile acids are synthesized in the liver, 


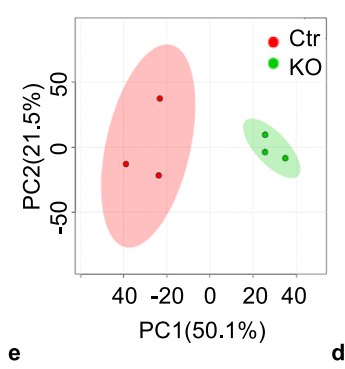

d

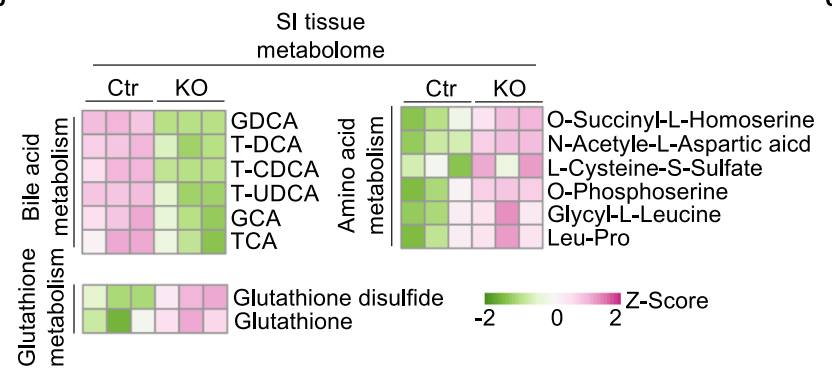

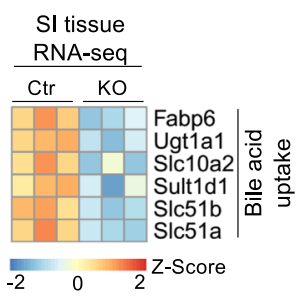
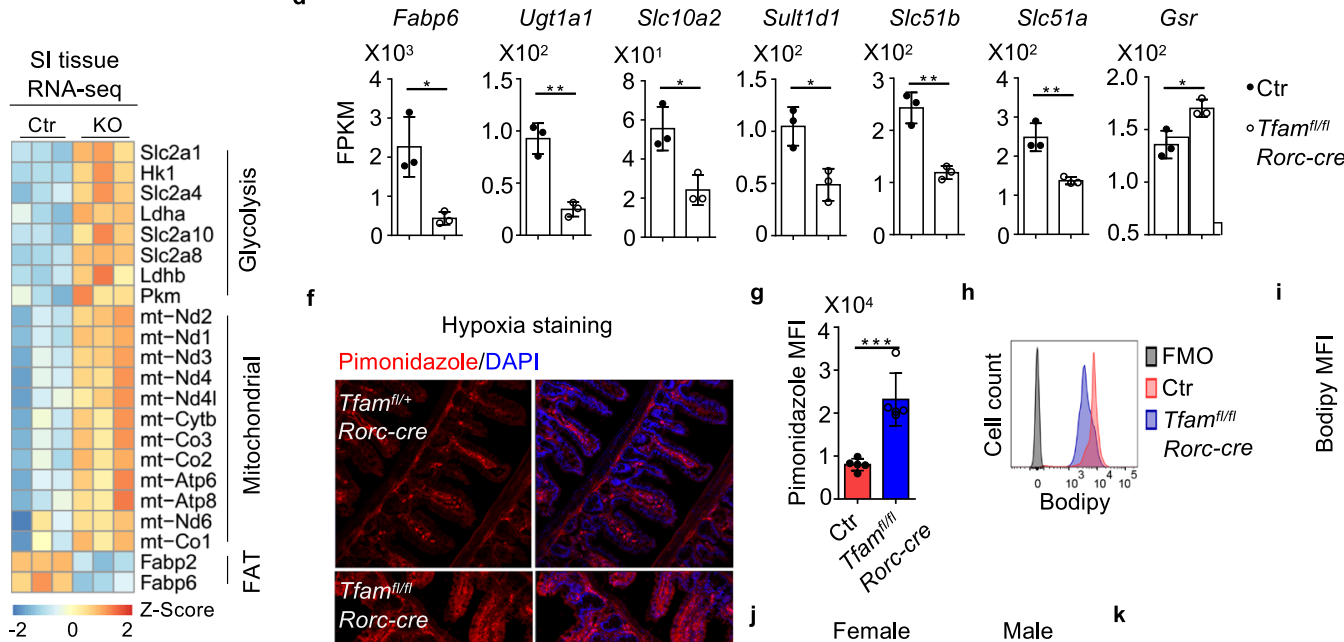

f

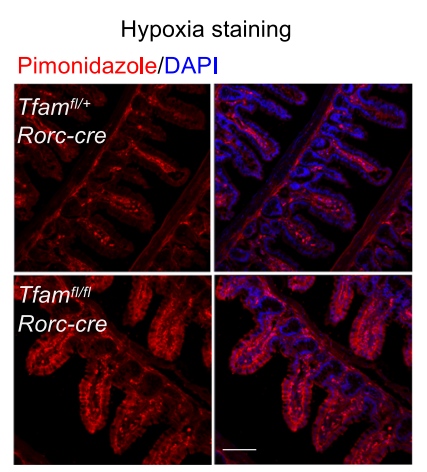

g

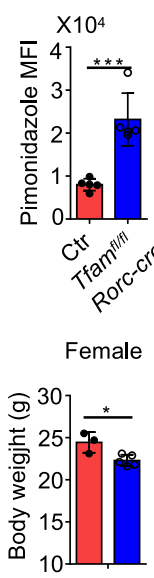

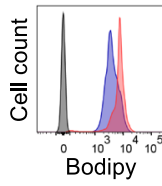

TFMO

$\square$ Ctr

पTfam ${ }^{\text {f/th }}$

Rorc-cre

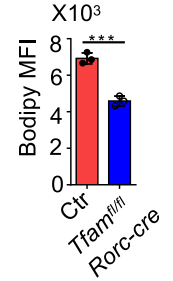

Male

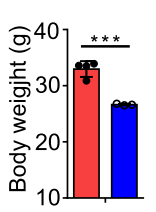

k
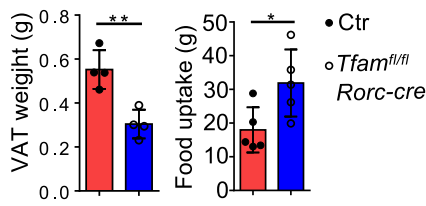

Fig. 7 Tfam deletion in ROR $\gamma \mathbf{t}^{+}$lymphocytes lead to global metabolomic changes in the small intestine. Ctr included Tfam ${ }^{+/+}$Rorc-cre and Tfam ${ }^{f l /+}$ Rorccre mice, while KO indicated Tfam ${ }^{f / / f l}$ Rorc-cre mice in a-e. a PCA analysis of the metabolome of small intestine tissues of 12-week-old Ctr and KO mice ( $n=$ 3 for each group). Each group included three individual mice. $\mathbf{b}$ Heatmap of the differentially regulated metabolites between small intestine tissues of $\mathrm{Ctr}$ and $\mathrm{KO}$ groups identified by the metabolome analysis. Metabolites were ranked in a descending order based on the fold changes of abundance ( $\mathrm{Ctr} / \mathrm{KO}$; $\mathrm{KO} / \mathrm{Ctr}$ ). c Heatmap of indicated gene expression of small intestine tissue RNA-seq of $\mathrm{Ctr}$ and $\mathrm{KO}$ mice as shown in Fig. 5a. Genes were ranked in a descending order based on the fold changes of expression ( $\mathrm{Ctr} / \mathrm{KO})$. $\mathbf{d}$ RNA-seq FPKM values of indicated genes in small intestine tissues of the mice $(n=$ 3) (Fabp6, ${ }^{\star} P=0.0155 ;$ Ugt1a1, ${ }^{\star \star} P=0.0019 ;$ Slc10a2, ${ }^{\star} P=0.0162$; Sult1d1, ${ }^{\star} P=0.0158 ;$ Slc51b, ${ }^{\star \star} P=0.0027 ;$ Slc51a, ${ }^{\star \star} P=0.0066 ;$ Gsr, ${ }^{\star} P=0.0186$ ). e Heatmap of DEGs in small intestine tissues of the mice identified by RNA-seq $(n=3)$. Genes were ranked in a descending order based on the fold changes of expression (KO/Ctr). Ctr included $\mathrm{Tfam}^{+/+}, \mathrm{Tfam}^{\mathrm{fl} /+}, \mathrm{Tfam}^{\mathrm{fl} / \mathrm{fl}}, \mathrm{Tfam}{ }^{+/}+$Rorc-cre, and Tfam ${ }^{\mathrm{fl} /}+$ Rorc-cre mice in $\mathbf{g}-\mathbf{k}$. $\mathbf{f}$ Confocal analysis of hypoxia by pimonidazole staining in the small intestine (ileum) of 12-week-old mice with indicated genotypes. Red, pimonidazole staining. Blue, DAPI staining. Scale bar, $200 \mu \mathrm{m}$. Representative data of three independent experiments. $\mathbf{g}$ Pimonidazole MFI in the epithelial cells shown in $\mathbf{f}(n=5$ for each group) ( $\left.{ }^{\star \star \star} P=0.0006\right)$. Compiled data from one experiment. $\mathbf{h}$ Bodipy uptake in small intestine epithelial cells from Ctr and Tfam ${ }^{f l / f l}$ Rorc-cre mice measured by flow cytometry. Representative data of two independent experiments. $\mathbf{i}$ Bodipy MFl in the epithelial cells as shown in $\mathbf{h}(n=3$ for each group) $\left.{ }^{\star \star \star} P=0.0006\right)$. Compiled data from one experiment. $\mathbf{j}$ Body weight of 5 -month-old female $\mathrm{Ctr}(n=3)$ and $\mathrm{Tfam}{ }^{f l / f l}$ Rorc-cre mice $(n=5)$ and male $\mathrm{Ctr}$ $(n=4)$ and Tfam ${ }^{f l / f l}$ Rorc-cre mice $(n=3)$ (female, ${ }^{\star} P=0.0169$; male, ${ }^{\star \star \star} P=0.0006$ ). Compiled data from two independent experiments. $\mathbf{k}$ Visceral adipose tissue (VAT) weight $(n=4)$ and 4-day-food uptake $(n=5)$ in 5-month-old mice with indicated genotypes (VAT, ${ }^{\star \star} P=0.0039 ;$ food uptake, ${ }^{\star} P=$ 0.0321). Compiled data from two independent experiments. Data are shown as mean \pm SD in $\mathbf{d}, \mathbf{g}$, i-k.

secreted into bile and most of them (95\%) are reabsorbed in the small intestine $e^{65}$, the reduction of bile acids could be a result of their compromised reabsorption in $T f a m^{f l} / f l$ Rorc-cre mice that had small intestine tissue remodeling. Consistent with this notion, the expression of several genes involved bile acid uptake (i.e., Fabp6, Ugt1a1, Slc10a2, Sult1d1, Slc51b, Slc51a) ${ }^{66}$ were significantly decreased in the small intestine tissues of $T f a \mathrm{~m}^{\mathrm{fl} / \mathrm{fl}} \mathrm{Rorc}$-cre mice (Fig. 7c, d).

Metabolome analysis also identified that several metabolites involved in glutathione metabolism (e.g., glutathione (GSH) and glutathione-disulfide (GSSG)) as well as mitochondria oxidative phosphorylation (e.g., a-ketoglutarate and 2-hydroxyglutarate) were increased in the small intestine tissues of Tfam ${ }^{f l f l}$ Rorc-cre mice (Fig. 7b and Supplementary Fig. 8c). Expression of glutathione reductase (Gsr), a key enzyme to produce glutathione in the cells, was increased in the small intestine tissues of Tfam $\mathrm{fl}^{\mathrm{l}}$ ${ }^{f}$ Rorc-cre mice (Fig. 7d), suggesting a compensatory elevation of antioxidants to protect tissue damage and inflammation, presumably due to oxidative stress. Indeed, several key components involved glycolysis (Slc2a1, Slc2a4, Slc2a8, Hk1, Pkm, Ldha, $L d h b)$ and most of the mitochondrial genes were up-regulated in the small intestine tissues of $T f a m^{f l / f l}$ Rorc-cre mice compared with 
littermate control mice (Fig. 7e), which could lead to enhanced oxidative stress. In line with increased tissue glycolysis and oxidative phosphorylation (OXPHOS) that consume oxygen, more hypoxic milieu was detected in the small intestine epithelial cells of $T f a m^{f l f l}$ Rorc-cre mice compared with their littermate controls as measured by pimonidazole staining (Fig. 7f, g).

RNA-seq results further showed that the fatty acid uptake transporters (FAT), Fabp2 and Fabp6 (a gene also involved in bile acid transport ${ }^{67}$ ), were down-regulated in the small intestine tissues of Tfam ${ }^{f l f l}$ Rorc-cre mice compared with littermate control mice (Fig. 7c, e). Fatty acid uptake, indicated by Bodipy FL C16 (a fluorescence fatty acid analog), was reduced in the small intestine epithelial cells of $T f^{\prime} m^{f l / f l}$ Rorc-cre mice (Fig. 7h, i). Consistently, $\mathrm{Tfam}^{f l / f l}$ Rorc-cre mice showed a reduction of body weight and fat weight, despite of increased food intake compared with littermate control mice (Fig. 7j, k). Collectively, our results supported a model that gut tissue microenvironment shapes $\gamma \delta \mathrm{T} 17$ cell metabolic and transcriptional programs. Metabolic changes in the small intestine tissues of $\mathrm{Tfam}^{\text {fl/fl }}$ Rorc-cre mice may cause alteration of global gene expression, which reciprocally influences tissue metabolism, remodeling, and inflammation (Supplementary Fig. 8e).

\section{Discussion}

Metabolism, such as glycolysis and mitochondrial OXPHOS, is not merely for energy generation, but also generates metabolites critical for immune cell differentiation, maintenance, and/or function $^{1}$. Direct measurement of metabolome, oxygen consumption rate (OCR), and extra-cellular acidification rate (ECAR) in rare immune cells such as $\gamma \delta \mathrm{T}$ cells, especially $\gamma \delta \mathrm{T} 17$ cells, has been technically challenging due to limited cell number recovered from mice (about 10,000 $\gamma \delta \mathrm{T} 17$ cells per mouse spleen). In this study, we took a genetic approach to ablate Tfam, a crucial transcription factor to regulate mitochondrial respiration gene replication and expression, in $\gamma \delta \mathrm{T}$ cells and ROR $\gamma \mathrm{t}^{+}$ lymphocytes usingTfam ${ }^{f l f l}$ Tcrd ${ }^{C r e E R}$ and Tfam ${ }^{f l / f l}$ Rorc-cre mice, respectively. Our data showed that Tfam-mediated mitochondrial metabolism was important for the maintenance of $\gamma \delta \mathrm{T} 17$ cells and ILC3s, but not for non- $\gamma \delta \mathrm{T} 17 \gamma \delta \mathrm{T}$ cells (including $\gamma \delta \mathrm{T} 1$ cells) or Th17 cells. Our work further revealed a critical role of Tfam in $\gamma \delta \mathrm{T} 17$ cells to control small intestine tissue remodeling and metabolism.

Mechanistically, our data support a model that Tfam is essential for the maintenance of $\gamma \delta T 17$ cells. Consistent with this hypothesis, decreased proliferation of $\gamma \delta \mathrm{T} 17$ cells without changes in apoptosis was observed in Tfam ${ }^{f l / f l}$ Rorc-cre mice. Transcription factor PLZF has been shown to be critical for $\gamma \delta$ T17 cell development and proliferation ${ }^{45}$. PLZF expression was decreased in Tfam-deficient $\gamma \delta \mathrm{T} 17$ cells. The critical role of Tfam in ROR $\gamma \mathrm{t}$ $+\gamma \delta \mathrm{T} 17$ cell and ILC3 maintenance was further supported by the progressive reduction of these cells in $T f a m^{f l / f l}$ Rorc-cre mice. Of note, we cannot rule out the possibility that Tfam regulates $\gamma \delta \mathrm{T} 17$ cell development due to the short window of $\gamma \delta$ T17 cell development in the fetal thymus ${ }^{47}$, and the restricted deletion of Tfam in ROR $\gamma \mathrm{t}$-expressing $\gamma \delta \mathrm{T}$ cells in Tfam ${ }^{f l / f l}$ Rorc-cre mice. Although our genetic approaches using Tcrd CreER and Rorc-cre mice allowed us to focus on the regulation of $\gamma \delta \mathrm{T} 17$ cell maintenance, a recent study showed that $I l 7 r$-cre deletion of Maf severely affected the $\gamma \delta \mathrm{T} 17$ cell development ${ }^{68}$, warranting future detailed investigation of role of Tfam-mediated mitochondrial respiration in $\gamma \delta \mathrm{T} 17$ cell development.

The small intestine tissue remodeling (e.g., increased tuft cells) in Tfam $^{f l / f l}$ Rorc-cre mice was accompanied by small intestine lengthening and inflammation (e.g., enhanced type 2 responses), consistent with the crucial role of tuft cell-ILC2 circuit in regulation of small intestine tissue homeostasis ${ }^{38}$. It remains to be determined whether small intestine length will change in Rorcofp/gfp mice, which lack all ROR $\gamma$ t-expressing cells, include Th17 cells, $\gamma \delta \mathrm{T} 17$ cells, and ILC3s. However, these mice also develop increased incidence of thymoma with age, complicating the interpretation of age-dependent small intestine lengthening and tissue remodeling. The small intestine lengthening was observed in

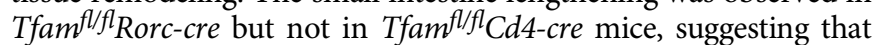
this phenotype may be CD4 ${ }^{+} \mathrm{T}$ cell independent in $T$ fam $^{f l / f l}$ Rorccre mice. Furthermore, Tfam ${ }^{f l f l}$ Rorc-cre mice had normal Th17 cells but reduced $\gamma \delta \mathrm{T} 17$ cells and ILC3s. Together, these data prompt us to conclude that Rorc-cre-mediated deletion of Tfam have $\gamma \delta \mathrm{T} 17$ and ILC3 cell type-specific effects associated with small intestine lengthening. However, our data do not rule out the possibility that the genetic strategy using Rorc-cre could have cellextrinsic or secondary effects on other cell types, which in turn affect small intestine length in vivo. In contrast to bone marrow transfer that at least partially restored the ILC3 compartment, we had not been able to restore $\gamma \delta \mathrm{T} 17$ cells in $T$ fam $^{\text {fl/fl }}$ Rorc-cre mice by adoptive transfer of purified wild-type $\gamma \delta \mathrm{T} 17$ cells. Thus, whether $\gamma \delta \mathrm{T} 17$ cells alone or together with other $\mathrm{ROR} \gamma \mathrm{t}^{+}$cells (i.e., ILC3s) to regulate the small intestine tissue remodeling and lengthening needs to be carefully determined.

Several potential mechanisms may count for increased type 2 immune responses (e.g., IL-13 production by ILC2s) in the small intestine of Tfam ${ }^{f l / f l}$ Rorc-cre mice. Our data showed that IL-22 could inhibit the IL-13-induced tuft cell differentiation in in vitro enteroid culture. Thus, reduction of IL-22-producing $\gamma \delta \mathrm{T} 17$ and ILC3s may relieve this negative regulation in vivo and enhances the differentiation of tuft cells, which have been shown to secrete IL-25 to promote the type 2 immune response in the gut ${ }^{35-38}$. In addition, mechanisms that regulate the balance of ILC2s and ILC3s in the gut have also been reported. For example, Ahr deficiency can increase ILC2s at the expense of ILC $3 s^{32,34}$. Vasoactive intestinal peptide (VIP) has been shown to regulate gut ILC2-ILC3 balance ${ }^{69-71}$. Thus, the reduction of $\gamma \delta T 17$ cells and ILC3s may also create a niche for expansion of type 2 immune responses in vivo. It was reported that IL-22 could activate ILC3s indirectly by inducing epithelial IL-18 during infection and IL-25-expressing epithelial cells could suppress IL22 production by ILC $3 \mathrm{~s}^{72,73}$. Our RNA-seq analysis showed that Ill1 was indeed reduced in the small intestine of $T f a m^{f l / f l}$ Rorc-cre mice. However, because of normal production of IL-22 by Tfamdeficient ILC3s on a per cell basis, the mechanisms involving IL18 or IL-25-mediated inhibition of IL-22 expression by ILC3s are less likely.

The intracellular parasite Tritrichomonas spp. has been shown to promote the intestinal tuft cell-ILC2 circuit by secreting succinate, a metabolite acting on the tuft cells through the succinate receptor 1 (Sucnr1 $)^{74}$. Consistently, MNZ treatment reduced Tritricomonas spp. and abrogated the phenotypes of increased small intestine length in $T f a m^{f / f l}$ Rorc-cre mice. Of note, increased small intestine length was observed in Tfam ${ }^{f l f l}$ Rorc-cre mice compared with cohoused Tfam-sufficient littermate mice, suggesting that the phenotype could not be simply transferrable by microbiome/eukaryome. Future studies involve metagenomic studies to carefully determine the potential dysbiosis in $\mathrm{Tfam}^{\mathrm{fl} / \mathrm{l}}$ ${ }^{f}$ Rorc-cre mice and the impact of Tfam on the composition of gut microbiota, especially small intestinal flora. Also, the requirement or contribution of Tritrichomonas spp. to observed phenotypes of

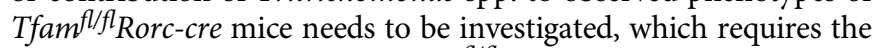
development of germ-free $T f_{a m}{ }^{f l f l}$ Rorc-cre mice with monoassociation of Tritrichomonas spp. and/or introduction of Tritrichomonas-free microbiome. Furthermore, bile acid metabolites changes in the small intestine tissues may also be due to altered microbiota-derived bile acid metabolism in these mice. 
Thus, future detailed investigation is needed to understand the role of the microbiome and/or eukaryome including Tritrichomonas spp. in regulation of small intestine tissue homeostasis in Tfam flifl Rorc-cre mice.

It has been shown that oxidative stress plays an essential role in the pathogenesis and progression of inflammatory bowel disease $^{75}$. Global metabolome study of small intestine tissues of $T f a m^{f l f l}$ Rorc-cre mice indicated an enhanced oxidative stress and hypoxic environment in the gut. Although up-regulated type 2 immune responses led to better helminth clearance, the enhanced inflammation in the small intestine of Tfam fl/flRorc-cre mice under the steady state might further exacerbate metabolic imbalance and worsen tissue remodeling during inflammatory challenge. The tissue transcriptome and metabolome analyses of Tfam ${ }^{\text {fl/fl}}$ Rorc-cre mice further showed decreased uptake of fatty acids and bile acids in the small intestine, consistent with less body weight. The increased small intestine length may thus reflect an adaptation to the energy and nutrition malfunction due to perturbation of mitochondrial activity in Tfam ${ }^{f l / f l}$ Rorc-cre mice.

In summary, our study highlighted the essential role of Tfam in the maintenance of selected IL-17-producing immune cells $(\gamma \delta \mathrm{T} 17$ and ILC3s), and may serve as a model for further investigations to elucidate the role of mitochondrial metabolism in these cells. Understanding metabolic regulation of the gut immune-epithelial cell interactions may provide therapeutic targets to control the small intestine tissue homeostasis and immunity in health and disease.

\section{Methods}

Mice. Mice used in this study were maintained in specific-pathogen-free (SPF) conditions at the University of Florida. All mouse studies were approved by the Animal Care and Use Committees of the University of Florida. Mice were littermate controlled and both male and female mice were used for experiments. Mice were used at 6- to 8-week-old age unless otherwise noted. Tfam ${ }^{f / f l}$ mice were kindly provided by Navdeep Chandel (Northwestern University), as previously described $^{22}$. C57BL/6, Tcrd ${ }^{\text {CreER }}$ mice, Il22 Cre mice, and Rorc-cre mice were purchased from Jackson Laboratory. For Tfam ${ }^{f l / f l}$ Tcrd ${ }^{C r e E R}$ mice, Tamoxifen was administered daily for 5 days at $2 \mathrm{mg} /$ mouse by intraperitoneal injection starting from 5-week-old age. For bone marrow transfer experiments, recipient mice were irradiated with $5 \mathrm{~Gy}$ gamma-ray (half lethal) followed by bone marrow transfer $\left(5 \times 10^{5}\right.$ cells per recipient) on the same day. Then, recipient mice received drinking water supplemented with $1 \mathrm{~g} / \mathrm{L}$ ampicillin for 2 weeks. For BrdU incorporation experiment, $2 \mathrm{mg}$ BrdU were i.p. injected into each mouse with indicated genotypes twice with a 12 -h interval. Mice were sacrificed $12 \mathrm{~h}$ after the second BrdU injection. For metronidazole treatment, 5-6-week-old mice with indicated genotypes were treated with drinking water supplemented with $2.5 \mathrm{~g} / \mathrm{L}$ metronidazole for 3 weeks. BrdU staining in lymphocytes were performed with PhaseFlow $^{\text {tx }}$ Alexa Fluor ${ }^{\circledR} 647$ BrdU Kit (Biolegend, Cat\#370706). For Hpb infection experiments, mice were gavaged with $200 \mathrm{Hpb}$ infective third stage larvae (L3), a gift kindly provided by Joseph F Urban Jr. (USDA/ARS) and sacrificed at day14 after the infection. For anti-Thy1.2, anti-IL-4, and anti-IL-13 treatment experiments, mice were i.p. injected with anti-Thy1.2 (BioXCell, Cat\# BE0066, $250 \mu \mathrm{g} /$ mouse), anti-IL-4 (BioXCell, Cat\# BE0045, $100 \mu \mathrm{g} / \mathrm{mouse}$ ), or anti-IL-13 (InvivoGen, Cat\# mabg-mil13, $50 \mu \mathrm{g} /$ mouse) twice a week for 3 weeks.

Lymphocyte isolation and flow cytometry. Lymphocytes from thymus, spleen, peripheral lymph nodes, intestinal lamina propria, lung, fat, and skin were isolated as previously described ${ }^{22}$. Liver lymphocyte isolation were conducted by mechanically dissociation of liver tissues after perfusion of the mouse with $10 \mathrm{ml}$ sterile ice-cold phosphate-buffered saline (PBS) and then lysed with the red blood cell lysis buffer for $2 \mathrm{~min}$. The cells from each tissue then went through a $70 \mu \mathrm{m}$ filter (Sigma). The filtered cells from the thymus, spleen, and peripheral lymph nodes were ready to use for flow cytometry. The filtered cells from the liver, intestinal lamina propria, lung, fat, and skin were further purified by $37.5 \%$ and $75 \%$ Percoll gradient for $20 \mathrm{~min}$ spin at $1200 \mathrm{~g}$. For FACS analysis, cells were firstly stained with Live and Dead violet viability kit (Invitrogen, Cat\# L34955) or Zombie Aqua fixable viability kit (BioLegend, Cat\# 423102) and followed by nonspecific binding blocking antibody anti-CD16/32 (Thermo Fisher). Then cells were stained with other antibodies for surface molecule staining. For intracellular protein staining, cells were fixed and permeabilized with Foxp3 staining buffer kit (eBioscience, Cat\# 00-5523-00). For flow cytometry staining, all antibodies were used at 1:200 final dilution unless otherwise described. The antibodies used in the study: Anti-mouse CD3ع-FITC (Tonbo Biosciences, Cat\# 35-0031-U500), Antimouse CD3-eFluor710 (eBioscience, Cat\# 46-0032), Anti-mouse CD4-APC-
eFluor $^{\circledR 780}$ (eBioscience, Cat\#47-0041), Anti-human/mouse CD45RB-PE (eBioscience, Cat\# 12-0455-83), Anti-mouse CD16/CD32-FITC (Tonbo Biosciences, Cat\# 35-0161-U100), Anti-mouse CD45.1-APC-Cy7 (Tonbo Biosciences, Cat\# 25-0453-U100), Anti-human/Mouse-RORyt-PE (eBioscience, Cat\# 12-698882), Anti-mouse KLRG1-PerCP-eFluor 710 (eBioscience, Cat\# 46-5893-82), Antimouse IL-13-Alexa Fluor 488 (eBioscience, Cat\# 53-7133-82), Anti-human/mouse IL-22-APC (eBioscience, Cat\# 17-7222-82), Anti-mouse CD45.1-PerCP-Cy5.5 (eBioscience, Cat\# 45-0453-82), Anti-mouse CD45.2-PerCP-Cy5.5 (eBioscience, Cat\# 45-0454-82), Anti-GATA3 (BD Biosciences, Cat\# 558686), Anti-mouse/ human IL-5-Brilliant Violet 421 (BioLegend, Cat\# 504311), Anti-mouse Foxp3eFluor 450 (eBioscience, Cat\# 48-4875-82), Anti-mouse CD4-APC-Cy7 (Tonbo Biosciences, Cat\# 25-0041-U100), Anti-mouse TCR $\beta$-PerCP-Cy5.5 (Tonbo Biosciences, Cat\# 65-5961-U100), Anti-mouse TCR $\beta$-eFluor 450 (eBioscience, Cat\# 48 5961-82), Anti-mouse CD8a-APC-Cy7 (BioLegend, Cat\# 100714), Anti-human/ mouse CD44-APC (eBioscience, Cat\# 17-0441-83), Anti-mouse CD62L-PE-Cy7 (eBioscience, Cat\# 25-0621-82), Anti-mouse IL-17A-PerCP-Cy5.5 (Invitrogen, Cat\# 45-7177-82), Anti-mouse IFN $\gamma$-APC (eBioscience, Cat\# 17-7311-82), Anti-DCLK1 (Abcam, Cat\# ab31704, 1:500 dilution), Anti-V 2 2-FITC (Biolegend, Cat\# 137704) Anti-cKit-PE-Cy7 (eBioscience, Cat\# 25-1171-82), Anti-mouse Ki-67-PE-cy7 (BD Biosciences, Cat\# 561283). Anti-V $\gamma 4$ antibody (Clone: 17D1, 1:100 dilution) was previously described ${ }^{76}$. For cytokine staining, unless otherwise noted, cells were stimulated with $50 \mathrm{ng} / \mathrm{ml}$ PMA and $500 \mathrm{ng} / \mathrm{ml}$ ionomycin in IMDM medium (supplemented with 5\% FBS, $100 \mu \mathrm{g} / \mathrm{ml}$ penicillin/streptomycin, $2 \mathrm{mM}$ L-glutamine) for $4 \mathrm{~h}$ and Brefeldin A $(2 \mu \mathrm{g} / \mathrm{ml})$ was added $2 \mathrm{~h}$ before cells were harvested. The gating strategy of different immune cell populations shown in Supplementary Fig. 2 BD FACSCantoII was used for FACS data collection. BD FACS Diva v8.0.2 was used to collect flow cytometry data. FlowJo software (version 10.2) was used for FACS data analysis. Sony sorter (SH800) was used for cell sorting.

Quantitative PCR. For quantification of gene expression, total RNA was isolated by RNeasy Micro kit (Qiagen) and reversely transcribed by GoScript ${ }^{\mathrm{TM}}$ Reverse Transcription kit (Promega). For quantification of mitochondrial DNA content, total DNA was isolated with DNeasy Blood \&Tissue Kit (Qiagen). Quantitative real-time PCR was performed on CFX connect Real-Time PCR Detection System (Bio-Rad). SYBR Green (Bio-Rad) and gene-specific primers were used for each gene. Data are presented as technical triplicates unless otherwise indicated in the legend. All primers used are listed in Supplementary Table 6.

Cellular ATP measurement. Cellular ATP from sorted $\gamma \delta \mathrm{T} 1$ or $\gamma \delta \mathrm{T} 17$ cells $(5000$ cells per assay well) was extracted by adding $100 \mu \mathrm{l} 0.5 \%$ trichloroacetic acid (Sigma, T6399). ATP measurement was performed with the ENLITEN ${ }^{\circledR}$ ATP Assay System Bioluminescence Detection Kit (Promega, FF2000). luminescence was detected using Synergy H1 microplate reader (BioTek).

Fatty acid uptake test. For small intestine epithelial cell isolation, the small intestine was cut open into $0.5-1 \mathrm{~cm}$ piece and washed with ice-cold sterile PBS for three times. Tissues were transferred into sterile calcium and magnesium-free HBSS containing HEPES $(20 \mathrm{mM})$, EDTA $(10 \mathrm{mM})$, and $1 \%$ FBS and shaken on ice every 1-2 min for $20 \mathrm{~min}$. The cells in the supernatant were collected and then enriched by centrifuging at $800 \mathrm{~g}$ for $5 \mathrm{~min}$ at $4{ }^{\circ} \mathrm{C}$. Cells were digested with $0.25 \%$ trypsin at $37^{\circ} \mathrm{C}$ for $1 \mathrm{~min}$ into single-cell suspension and washed with ice-cold sterile PBS for further use. For fatty acid uptake test, small intestine epithelial cells were stained with Bodipy FL C16 (Thermo) in PBS for 5 min. Data were collected by flow cytometry (BDCantoII) or a confocal microscope (Zeiss 710 confocal microscope).

Immunofluorescence staining and confocal microscope analysis. Small intestine tissues were fixed overnight with $4 \%$ PFA. After three times PBS wash at room temperature and $0.5 \%$ Triton-PBS permeabilization for $15 \mathrm{~min}$, tissue swiss-rolls were embedded in OCT compound (Tissue-Tek). Frozen sections at $10 \mu \mathrm{m}$ were put on the slides followed by antibody and 4',6-diamidino-2-phenylindole (DAPI) staining. For the primary antibody staining, anti-CD3-PE (BD, Cat\#553063, 1:200 dilution), anti-KLRG1-Alexa488 (Invitrogen, Cat\#53-5893-82, 1:200 dilution), and anti-DCLK1 (Abcam, Cat\# ab31704, 1:800 dilution) were used under $4{ }^{\circ} \mathrm{C}$ overnight. For DCLK1 secondary antibody staining, Anti-rabbit IgG-Alexa Fluor 488 (Thermal Fisher, Cat\# A11008, 1:2000 dilution) was used at room temperature for $1 \mathrm{~h}$. Data were collected by a confocal microscope (Zeiss 710 confocal microscope). ZEN 2011 v14.0.10.201 was used to collect confocal images.

Hematoxylin and eosin (H\&E) staining and PAS staining. Tissues for H\&E staining and PAS staining were processed as previously described ${ }^{22}$. Briefly, tissues were fixed overnight in $4 \%$ PFA. After washing and embedding in paraffin, tissues were cut into slices and put on the slides followed by dewaxing and dehydration. Then, tissue slices were stained with H\&E or periodic acid and Schiff reagent. Histological scoring was performed under the following criteria: villous architecture (normal $=0$, widened due to laminar propria inflammatory infiltration $=1$, blunt $=2$ ); IELs (no $=0$, rare $(<5 /$ villus $)=1$, frequent $=2)$; crypt hyperplasia $($ no $=1$, yes $=1)$; goblet cell hyperplasia $($ no $=1$, yes $=1)$; muscularis propria 
hypertrophy ( $\mathrm{no}=1$, yes $=1$ ); acute inflammation $($ no $=0$, yes $=1)$. Total scores were summarized and quantified.

RNA-Seq analyses. For RNA-Seq analyses of $\gamma \delta \mathrm{T} 17$ cells, $2 \times 10^{3}$ sorted $\gamma \delta \mathrm{T} 17$ cells from the spleen, small intestine, or large intestine of control or Tfam fllfl Rorc- $^{-}$ cre littermate mice were used. RNA was isolated by RNAeasy Micro Kit. cDNA generation was performed with SMART-Seq ${ }^{\circledR}$ HT Kit (Takara). Sequencing libraries were generated with Nextera ${ }^{\circledR}$ XT DNA Library Preparation Kit (Illumina). For RNA-Seq analyses of small intestine tissues, control or Tfam $\mathrm{Q}^{f / f l}$ Rorc-cre littermate mice were used. RNA was isolated by RNAeasy Mini Kit (Qiagen). Libraries were generated with NEBNext Ultra II RNA library Prep Kit (NEB). Libraries were sequenced on an Illumina HiSeq 2500 instrument to produce $50 \mathrm{bp}$ single-end reads. FastQC (v0.11.5) was used to ensure high per-base sequence quality of reads. Sequenced reads were mapped and raw count values quantified with STAR (v2.7.4a) ${ }^{77}$ to the Mus musculus genome (GRCm38/mm10 assembly) and filtered for uniquely mapped reads. Quantitated mRNA expression levels, FPKM aligned reads, were calculated based on exon regions using RSEM $(\mathrm{v} 1.2 .25)^{78}$. Differentially expressed genes (max FPKM $\geq 1$, fold change $\geq 1.5, q$ value $\leq 0.05$ ) were identified by DESeq2 (v1.26.0) analysis ${ }^{79}$. Gene Set Enrichment Analysis (GSEA) was performed for GO and KEGG analysis (MSigDB v6.0). Log2 transformed FPKM values were used for PCA in R with the prcomp function and then visualized using the rgl package (v0.100.30). Euclidian distance comparison was calculated based on the distance between the individual spleen samples and the mean intestine centroid coordinate, and the distance between the mean small intestine centroid coordinate and the individual large intestine samples. Heatmaps were created using the R package pheatmap (v1.0.12).

In vitro enteroid culture. Small intestine crypts were isolated from the small intestine of 4-8-week-old C57BL/6 mice and embedded in a 50\% Matrigel (Corning 352231) solution in complete enteroid media consisting of $50 \mathrm{ng} / \mathrm{ml}$ recombinant mouse EGF (Peprotech 315-09), $50 \mathrm{ng} / \mathrm{ml}$ recombinant murine noggin (Peprotech 250-38), and $50 \mathrm{ng} / \mathrm{ml}$ recombinant mouse $\mathrm{r}$-spondin (R\&D Systems $7150-R S)$ as previously described ${ }^{80}$. Enteroids were passaged a minimum of one time prior to experimentation in 24-well plates at approximately 150 organoids per well. For whole mount immunofluorescent staining, samples were fixed in $4 \%$ paraformaldehyde for $30 \mathrm{~min}$ at room temperature, permeabilized with $0.1 \%$ Triton X-100 for $30 \mathrm{~min}$ at room temperature, then blocked in an ice-cold PBS solution containing 5\% normal goat serum and 1\% BSA for $60 \mathrm{~min}$. Fixed organoids were then incubated overnight at $4^{\circ} \mathrm{C}$ with DCLK1 antibody (Abcam, Cat\# ab31704, 1:400 dilution) and followed by overnight at $4{ }^{\circ} \mathrm{C}$ with Alexa Fluor 488 goat anti-rabbit secondary antibodies (Thermal Fisher, Cat\# A11008, 1:2000 dilution). Samples were subsequently counterstained with a 1:5000 DAPI solution (Fisher Scientific 62248) for $1 \mathrm{~h}$ at room temperature and stored at $4{ }^{\circ} \mathrm{C}$ until visualization using a confocal microscope (Zeiss 710 confocal microscope).

Hydrodynamic gene delivery of IL-22 in vivo. IL-22 plasmid DNA was introduced into mice using a hydrodynamic tail vein injection-based gene transfer technique as previously described ${ }^{34}$. Briefly, plasmid DNA was diluted in TransITEE Hydrodynamic Delivery Solution (Mirus) $(5 \mu \mathrm{g} / \mathrm{ml})$ in a volume equal to $10 \%$ body weight $(0.1 \mathrm{ml} / \mathrm{g})$. The DNA solution was injected into mice through the tail vein using a 30-gauge needle within a time period of $5 \mathrm{~s}$. Hydrodynamic injection was performed in mice at the age of 6 weeks old. Mice were sacrificed 4 weeks after the hydrodynamic injection. To ensure the success of delivery, the tissue RNA was prepared and monitored for IL-22 target gene (Reg3g) expression.

Tissue metabolome analysis. Tissue samples were extracted with prenormalization to the sample protein content of $500 \mu \mathrm{g} / \mathrm{ml}$ as previously described $^{81}$. Global metabolomics profiling was performed on a Thermo QExactive Oribtrap mass spectrometer coupled to a Dionex UHPLC and autosampler. Samples were analyzed in both positive and negative heated electrospray ionization with a mass resolution of 35,000 . Separation was achieved by gradient elution on an ACE 18 -pfp $100 \times 2.1 \mathrm{~mm}, 2 \mu \mathrm{m}$ column with a flow rate of $350 \mu \mathrm{l} /$ min at $25^{\circ} \mathrm{C}$ column temperature. Mobile phase A was $0.1 \%$ formic acid in water and mobile phase B was unmodified acetonitrile. Injection volume was $4 \mu \mathrm{L}$ for negative ionization and $2 \mu \mathrm{L}$ for positive ionization. Data from positive and negative ion modes were separately subjected to statistical analyses. All subsequent data analyses were normalized to the sum of metabolites for each sample. MZmine2 (freeware, v2.53) was used for alignment, gap filling, and metabolite identification ${ }^{82}$. All adducts and complexes were identified and removed from the data set.

\section{Quantification and statistical analysis}

All data contain at least $n=3$ per group and are shown as mean \pm SD. Two-sided Student's $t$-test was performed for statistical analysis by GraphPad Prism 7.04 software package in the manuscript unless otherwise noted. $P$ values were indicated with asterisks $\left({ }^{*} P \leq 0.05\right.$; $\left.{ }^{* *} P \leq 0.01 ;{ }^{* * *} P \leq 0.001 ;{ }^{* * * *} P \leq 0.0001\right)$ in the figures. No multiple comparison was performed unless otherwise noted. PCA for metabolome was performed in Metaboanalyst 3.0 on the sum normalized, $\log 2$ transformed, and autoscaled data ${ }^{83}$.

Reporting summary. Further information on research design is available in the Nature Research Reporting Summary linked to this article.

\section{Data availability}

All data supporting the findings of this study are available within the article and its supplementary materials and from the corresponding author upon reasonable request. The RNA-sequencing data of splenic, small intestine and large intestine control and Tfam-deficient $\gamma \delta \mathrm{T} 17$ cells, and small intestine tissues of control and Tfam ${ }^{f l / f l}$ Rorc-cre mice generated in this study have been deposited in the NCBI database under accession code GSE152535. Source data are provided with this paper.

Received: 30 December 2020; Accepted: 28 June 2021; Published online: 22 July 2021

\section{References}

1. Mehta, M. M., Weinberg, S. E. \& Chandel, N. S. Mitochondrial control of immunity: beyond ATP. Nat. Rev. Immunol. 17, 608-620 (2017).

2. Puleston, D. J., Villa, M. \& Pearce, E. L. Ancillary activity: beyond core metabolism in immune cells. Cell Metab. 26, 131-141 (2017).

3. Weinberg, S. E. et al. Mitochondrial complex III is essential for suppressive function of regulatory T cells. Nature 565, 495-499 (2019).

4. Xu, T. et al. Metabolic control of TH17 and induced Treg cell balance by an epigenetic mechanism. Nature 548, 228-233 (2017)

5. Joseph, A. M., Monticelli, L. A. \& Sonnenberg, G. F. Metabolic regulation of innate and adaptive lymphocyte effector responses. Immunol. Rev. 286, 137-147 (2018)

6. Di Luccia, B., Gilfillan, S., Cella, M., Colonna, M. \& Huang, S. C. ILC3s integrate glycolysis and mitochondrial production of reactive oxygen species to fulfill activation demands. J. Exp. Med. 216, 2231-2241 (2019).

7. Shichita, T. et al. Pivotal role of cerebral interleukin-17-producing gammadeltaT cells in the delayed phase of ischemic brain injury. Nat. Med. 15, 946-950 (2009)

8. Cai, Y. et al. Pivotal role of dermal IL-17-producing gammadelta T cells in skin inflammation. Immunity 35, 596-610 (2011).

9. $\mathrm{Wu}, \mathrm{P}$. et al. gammadeltaT17 cells promote the accumulation and expansion of myeloid-derived suppressor cells in human colorectal cancer. Immunity 40, 785-800 (2014).

10. Papotto, P. H., Reinhardt, A., Prinz, I. \& Silva-Santos, B. Innately versatile: gammadelta17 $\mathrm{T}$ cells in inflammatory and autoimmune diseases. $J$. Autoimmun. 87, 26-37 (2018).

11. Simonian, P. L. et al. gammadelta $\mathrm{T}$ cells protect against lung fibrosis via IL 22. J. Exp. Med. 207, 2239-2253 (2010)

12. Coffelt, S. B. et al. IL-17-producing gammadelta T cells and neutrophils conspire to promote breast cancer metastasis. Nature 522, 345-348 (2015).

13. Guo, X. J. et al. Lung gammadelta $\mathrm{T}$ cells mediate protective responses during neonatal influenza infection that are associated with type 2. Immunity 49, 531-544.e536 (2018).

14. Gronke, K. et al. Interleukin-22 protects intestinal stem cells against genotoxic stress. Nature 566, 249-253 (2019).

15. Schon, E. A., DiMauro, S. \& Hirano, M. Human mitochondrial DNA: roles of inherited and somatic mutations. Nat. Rev. Genet. 13, 878-890 (2012).

16. Kazachkova, N., Ramos, A., Santos, C. \& Lima, M. Mitochondrial DNA damage patterns and aging: revising the evidences for humans and mice. Aging Dis. 4, 337-350 (2013).

17. Picca, A. \& Lezza, A. M. Regulation of mitochondrial biogenesis through TFAM-mitochondrial DNA interactions: Useful insights from aging and calorie restriction studies. Mitochondrion 25, 67-75 (2015).

18. Baixauli, F. et al. Mitochondrial respiration controls lysosomal function during inflammatory T cell responses. Cell Metab. 22, 485-498 (2015).

19. Kang, D., Kim, S. H. \& Hamasaki, N. Mitochondrial transcription factor A (TFAM): roles in maintenance of mtDNA and cellular functions. Mitochondrion 7, 39-44 (2007).

20. Larsson, N. G. et al. Mitochondrial transcription factor A is necessary for mtDNA maintenance and embryogenesis in mice. Nat. Genet. 18, 231-236 (1998).

21. Liu, X. et al. Regulation of mitochondrial biogenesis in erythropoiesis by mTORC1-mediated protein translation. Nat. Cell Biol. 19, 626-638 (2017).

22. $\mathrm{Fu}, \mathrm{Z}$. et al. Requirement of mitochondrial transcription factor $\mathrm{A}$ in tissueresident regulatory $\mathrm{T}$ cell maintenance and function. Cell Rep. 28, 159-171. e154 (2019). 
23. Konkel, J. E. \& Chen, W. Balancing acts: the role of TGF-beta in the mucosal immune system. Trends Mol. Med. 17, 668-676 (2011).

24. Hang, S. et al. Bile acid metabolites control TH17 and Treg cell differentiation. Nature 576, 143-148 (2019).

25. Song, X. et al. Microbial bile acid metabolites modulate gut RORgamma(+) regulatory T cell homeostasis. Nature 577, 410-415 (2020).

26. Faria, A. M. C., Reis, B. S. \& Mucida, D. Tissue adaptation: Implications for gut immunity and tolerance. J. Exp. Med. 214, 1211-1226 (2017).

27. Lavelle, A. \& Sokol, H. Gut microbiota-derived metabolites as key actors in inflammatory bowel disease. Nat. Rev. Gastroenterol. Hepatol. 17, 223-237 (2020).

28. Hoeppli, R. E., Wu, D., Cook, L. \& Levings, M. K. The environment of regulatory $\mathrm{T}$ cell biology: cytokines, metabolites, and the microbiome. Front. Immunol. 6, 61 (2015).

29. Zhou, L. AHR function in lymphocytes: emerging concepts. Trends Immunol. 37, 17-31 (2016)

30. Li, S., Bostick, J. W. \& Zhou, L. Regulation of innate lymphoid cells by aryl hydrocarbon receptor. Front. Immunol. 8, 1909 (2017).

31. Stockinger, B., Di Meglio, P., Gialitakis, M. \& Duarte, J. H. The aryl hydrocarbon receptor: multitasking in the immune system. Annu Rev. Immunol. 32, 403-432 (2014).

32. Li, S. et al. Aryl hydrocarbon receptor signaling cell intrinsically inhibits intestinal group 2 innate lymphoid cell function. Immunity 49, 915-928.e915 (2018).

33. Ye, J. et al. The aryl hydrocarbon receptor preferentially marks and promotes gut regulatory T cells. Cell Rep. 21, 2277-2290 (2017).

34. Qiu, J. et al. The aryl hydrocarbon receptor regulates gut immunity through modulation of innate lymphoid cells. Immunity 36, 92-104 (2012).

35. Howitt, M. R. et al. Tuft cells, taste-chemosensory cells, orchestrate parasite type 2 immunity in the gut. Science 351, 1329-1333 (2016)

36. von Moltke, J., Ji, M., Liang, H. E. \& Locksley, R. M. Tuft-cell-derived IL-25 regulates an intestinal ILC2-epithelial response circuit. Nature 529, 221-225 (2016).

37. Gerbe, F. et al. Intestinal epithelial tuft cells initiate type 2 mucosal immunity to helminth parasites. Nature 529, 226-230 (2016).

38. Schneider, C. et al. A metabolite-triggered tuft cell-ILC2 circuit drives small intestinal remodeling. Cell 174, 271-284.e214 (2018).

39. Corpuz, T. M. et al. Differential responsiveness of innate-like IL-17- and IFNgamma-producing gammadelta $\mathrm{T}$ cells to homeostatic cytokines. J. Immunol. 196, 645-654 (2016)

40. Sumaria, N., Grandjean, C. L., Silva-Santos, B. \& Pennington, D. J. Strong TCRgammadelta signaling prohibits thymic development of IL-17A-secreting gammadelta T cells. Cell Rep. 19, 2469-2476 (2017).

41. Shibata, K. et al. IFN-gamma-producing and IL-17-producing gammadelta $\mathrm{T}$ cells differentiate at distinct developmental stages in murine fetal thymus. $J$. Immunol. 192, 2210-2218 (2014).

42. Zhang, B. et al. Differential requirements of TCR signaling in homeostatic maintenance and function of dendritic epidermal T cells. J. Immunol. 195, 4282-4291 (2015).

43. Ivanov, I. I. et al. The orphan nuclear receptor RORgammat directs the differentiation program of proinflammatory IL-17+ T helper celld. Cell 126, 1121-1133 (2006).

44. Martin, B., Hirota, K., Cua, D. J., Stockinger, B. \& Veldhoen, M. Interleukin17-producing gammadelta $\mathrm{T}$ cells selectively expand in response to pathogen products and environmental signals. Immunity 31, 321-330 (2009).

45. Lu, Y., Cao, X., Zhang, X. \& Kovalovsky, D. PLZF controls the development of fetal-derived IL-17+Vgamma6+ gammadelta T cells. J. Immunol. 195, 4273-4281 (2015).

46. Garman, R. D., Doherty, P. J. \& Raulet, D. H. Diversity, rearrangement, and expression of murine T cell gamma genes. Cell 45, 733-742 (1986)

47. Haas, J. D. et al. Development of interleukin-17-producing gammadelta $\mathrm{T}$ cells is restricted to a functional embryonic wave. Immunity 37, 48-59 (2012).

48. Klose, C. S. N. et al. Differentiation of type 1 ILCs from a common progenitor to all helper-like innate lymphoid cell lineages. Cell 157, 340-356 (2014).

49. Xiong, L. et al. Ahr-Foxp3-RPRgt axis controls gut homing of CD4+ T cells by regulating GRP15. Scie. Immunol. 5, eaaz7277 (2020)

50. Ferdous, Z., Wei, V. M., Iozzo, R., Hook, M. \& Grande-Allen, K. J. Decorintransforming growth factor- interaction regulates matrix organization and mechanical characteristics of three-dimensional collagen matrices. J. Biol. Chem. 282, 35887-35898 (2007).

51. Murphy-Ullrich, J. E. \& Poczatek, M. Activation of latent TGF-beta by thrombospondin-1: mechanisms and physiology. Cytokine Growth Factor Rev. 11, 59-69 (2000)

52. Guca, E. et al. TGIF1 homeodomain interacts with Smad MH1 domain and represses TGF-beta signaling. Nucleic Acids Res. 46, 9220-9235 (2018).

53. Ihara, S., Hirata, Y. \& Koike, K. TGF-beta in inflammatory bowel disease: a key regulator of immune cells, epithelium, and the intestinal microbiota. J. Gastroenterol. 52, 777-787 (2017).
54. Chen, J. et al. NR4A transcription factors limit CAR T cell function in solid tumours. Nature 567, 530-534 (2019).

55. Doi, Y. et al. Orphan nuclear receptor NR4A2 expressed in T cells from multiple sclerosis mediates production of inflammatory cytokines. Proc. Natl Acad. Sci. USA 105, 8381-8386 (2008).

56. Zaiss, D. M. W., Gause, W. C., Osborne, L. C. \& Artis, D. Emerging functions of amphiregulin in orchestrating immunity, inflammation, and tissue repair. Immunity 42, 216-226 (2015).

57. Lin, C. C. et al. Bhlhe 40 controls cytokine production by $\mathrm{T}$ cells and is essential for pathogenicity in autoimmune neuroinflammation. Nat. Commun. 5, 3551 (2014).

58. $\mathrm{Du}, \mathrm{N}$. et al. EGR2 is critical for peripheral naive T-cell differentiation and the T-cell response to influenza. Proc. Natl Acad. Sci. USA 111, 16484-16489 (2014).

59. Zhou, X., Herbst-Robinson, K. J. \& Zhang, J. Visualizing dynamic activities of signaling enzymes using genetically encodable FRET-based biosensors from designs to applications. Methods Enzymol. 504, 317-340 (2012).

60. Murn, J., Alibert, O., Wu, N., Tendil, S. \& Gidrol, X. Prostaglandin E2 regulates B cell proliferation through a candidate tumor suppressor, Ptger4. J. Exp. Med. 205, 3091-3103 (2008).

61. Komori, T. Regulation of proliferation, differentiation and functions of osteoblasts by Runx2. Int. J. Mol. Sci. 20, 1694 (2019).

62. Zhou, W., Rowitz, B. M. \& Dailey, M. J. Insulin/IGF-1 enhances intestinal epithelial crypt proliferation through PI3K/Akt, and not ERK signaling in obese humans. Exp. Biol. Med. (Maywood) 243, 911-916 (2018).

63. Tripathi, D. et al. A TLR9 agonist promotes IL-22-dependent pancreatic islet allograft survival in type 1 diabetic mice. Nat. Commun. 7, 13896 (2016).

64. Vanaudenaerde, B. M. et al. Innate and adaptive interleukin-17-producing lymphocytes in chronic inflammatory lung disorders. Am. J. Respir. Crit. Care Med. 183, 977-986 (2011).

65. Chiang, J. Y. Bile acid metabolism and signaling. Compr. Physiol. 3, 1191-1212 (2013).

66. Dawson, P. A. \& Karpen, S. J. Intestinal transport and metabolism of bile acids. J. Lipid Res. 56, 1085-1099 (2015).

67. Gajda, A. M. \& Storch, J. Enterocyte fatty acid-binding proteins (FABPs): different functions of liver and intestinal FABPs in the intestine. Prostaglandins Leukot. Essent. Fatty Acids 93, 9-16 (2015).

68. Zuberbuehler, M. K. et al. The transcription factor c-Maf is essential for the commitment of IL-17-producing gammadelta T cells. Nat. Immunol. 20 73-85 (2019).

69. Talbot, J. et al. Feeding-dependent VIP neuron-ILC3 circuit regulates the intestinal barrier. Nature 579, 575-580 (2020).

70. Nussbaum, J. C. et al. Type 2 innate lymphoid cells control eosinophil homeostasis. Nature 502, 245-248 (2013).

71. Seillet, C. et al. The neuropeptide VIP confers anticipatory mucosal immunity by regulating ILC3 activity. Nat. Immunol. 21, 168-177 (2020).

72. Munoz, M. et al. Interleukin-22 induces interleukin-18 expression from epithelial cells during intestinal infection. Immunity 42, 321-331 (2015).

73. Sawa, S. et al. RORgammat+ innate lymphoid cells regulate intestinal homeostasis by integrating negative signals from the symbiotic microbiota. Nat. Immunol. 12, 320-326 (2011).

74. Nadjsombati, M. S. et al. Detection of succinate by intestinal tuft cells triggers a type 2 innate immune circuit. Immunity 49, 33-41.e37 (2018)

75. Tian, T., Wang, Z. \& Zhang, J. Pathomechanisms of oxidative stress in inflammatory bowel disease and potential antioxidant therapies. Oxid. Med. Cell Longev. 2017, 4535194 (2017).

76. Roark, C. L. et al. Subset-specific, uniform activation among V gamma 6/V delta $1+$ gamma delta $\mathrm{T}$ cells elicited by inflammation. J. Leukoc. Biol. 75, 68-75 (2004).

77. Dobin, A. et al. STAR: ultrafast universal RNA-seq aligner. Bioinformatics 29, 15-21 (2013).

78. Li, B. \& Dewey, C. N. RSEM: accurate transcript quantification from RNA-Seq data with or without a reference genome. BMC Bioinformatics 12, 323 (2011).

79. Love, M. I., Huber, W. \& Anders, S. Moderated estimation of fold change and dispersion for RNA-seq data with DESeq2. Genome Biol. 15, 550 (2014).

80. He, Z. et al. Campylobacter jejuni promotes colorectal tumorigenesis through the action of cytolethal distending toxin. Gut 68, 289-300 (2019).

81. Pinto, F. G., Mahmud, I., Harmon, T. A., Rubio, V. Y. \& Garrett, T. J. Rapid prostate cancer noninvasive biomarker screening using segmented flow mass spectrometry-based untargeted metabolomics. J. Proteome Res. (2020).

82. Pluskal, T., Castillo, S., Villar-Briones, A. \& Oresic, M. MZmine 2: modular framework for processing, visualizing, and analyzing mass spectrometry-based molecular profile data. BMC Bioinformatics 11, 395 (2010).

83. Pang, Z., Chong, J., Li, S. \& Xia, J. MetaboAnalystR 3.0: toward an optimized workflow for global metabolomics. Metabolites 10, https://doi.org/10.3390/ metabo10050186 (2020) 


\section{Acknowledgements}

We thank John Bostick, Jian Ye, Shainal Gandhi, Shiyang Li, and other members from Zhou lab for their help and suggestions. We thank the Genomics Facility (University of Chicago) for sequencing services and assistance. We thank Joy G. Cagmat from Dr. Garrett's lab for the help with the metabolome analysis. We thank Greg Tyler for his help with irradiation for the bone marrow transfer experiments. This work was made possible in part by NIH Instrumentation Grant 1S10 OD021676-01. L.Z. is a Pew Scholar in Biomedical Sciences supported by the Pew Charitable Trusts and an Investigator in the Pathogenesis of Infectious Disease supported by the Burroughs Wellcome Fund. The work was supported by the National Institutes of Health (AI132391 and DK105562 to L.Z.).

\section{Author contributions}

Z.F. and L.Z. designed the study. Z.F. and J.W.D. performed the experiments, and analyzed the data. L.X., M.W.D., K.N.O., and Z..E.C. performed the experiments. C.J. and T.J.G. provided reagent and expertise. L.Z. supervise the study. Z.F. and L.Z. wrote the manuscript with the input from other authors.

\section{Competing interests}

The authors declare no competing interests.

\section{Additional information}

Supplementary information The online version contains supplementary material available at https://doi.org/10.1038/s41467-021-24755-9.

\section{Correspondence and requests for materials should be addressed to L.Z.}

Peer review information Nature Communications thanks the anonymous reviewer(s) for their contribution to the peer review of this work.

Reprints and permission information is available at http://www.nature.com/reprints

Publisher's note Springer Nature remains neutral with regard to jurisdictional claims in published maps and institutional affiliations.

(c) Open Access This article is licensed under a Creative Commons Attribution 4.0 International License, which permits use, sharing, adaptation, distribution and reproduction in any medium or format, as long as you give appropriate credit to the original author(s) and the source, provide a link to the Creative Commons license, and indicate if changes were made. The images or other third party material in this article are included in the article's Creative Commons license, unless indicated otherwise in a credit line to the material. If material is not included in the article's Creative Commons license and your intended use is not permitted by statutory regulation or exceeds the permitted use, you will need to obtain permission directly from the copyright holder. To view a copy of this license, visit http://creativecommons.org/ licenses/by/4.0/.

(C) The Author(s) 2021 